\title{
1 Cloud properties over the Southern Ocean during the MARCUS field
}

\section{2 campaign}

3

4 Baike $\mathrm{Xi}^{1}$, Xiquan Dong ${ }^{1}$, Xiaojian Zheng ${ }^{1}$, and Peng $\mathrm{Wu}^{2}$

5

$6 \quad{ }^{1}$ Department of Hydrology and Atmospheric Sciences, University of Arizona, Tucson, AZ, USA

$7 \quad{ }^{2}$ Pacific Northwest National Laboratory, Richland, WA, USA

8

9 Correspondence: Baike Xi (baikex@ arizona.edu $)$

11 Abstract. To investigate the cloud properties over the Southern Ocean (SO), the MARCUS field campaign (41 to $69^{\circ} \mathrm{S} ; 60$ to $160^{\circ} \mathrm{E}$ ) was conducted from October 2017 to March 2018, using

13 ship-based measurements. To examine cloud properties over the mid-latitude and Polar regions,

14 the study domain is separated into northern (NSO) and southern (SSO) parts of the SO with a

15 demarcation line of $60^{\circ} \mathrm{S}$. The total cloud fractions $(C F \mathrm{~s})$ were $77.9 \%, 67.6 \%$, and $90.3 \%$ for

16 the entire domain, $\mathrm{NSO}$ and SSO, respectively, indicating that higher $C F$ s were observed in the

17 Polar region. Low-level clouds, deep cumulus, and shallow cumulus clouds are the three most

18 common cloud types over the SO. For single-layered low-level clouds, mixed-phase clouds

19 dominate with an occurrence frequency (Freq) of $54.5 \%$, while the Freq of the liquid and ice

20 clouds were $10.1 \%$ (most drizzling) and $17.4 \%$ (least drizzling). The meridional distributions of

21 low-level cloud boundaries are nearly independent of latitude, whereas the cloud temperatures

22 increased $\sim 8 \mathrm{~K}$ and atmospheric precipitable water vapor increased from $\sim 5 \mathrm{~mm}$ at $69^{\circ} \mathrm{S}$ to $\sim 18$

$23 \mathrm{~mm}$ at $43^{\circ} \mathrm{S}$. The mean cloud liquid water paths over NSO were much larger than those over SSO. 
24 Most liquid clouds occurred over NSO with very few over SSO, whereas more mixed-phase clouds occurred over SSO than over NSO. There were no significant differences for ice cloud Freq between NSO and SSO. These results will be valuable for advancing our understanding of the meridional and vertical distributions of clouds and can be used to improve model simulations over the SO.

\section{Introduction}

The Southern Ocean (SO) is one of the cloudiest and stormiest regions on the Earth (Chubb et al., 2013). The majority of the aerosols are naturally produced via oceanic sources given the remote environment. However, we have limited knowledge about cloud formation processes within such clean environments and their associated aerosol and cloud properties. The unique nature of the SO region features low-level supercooled liquid and mixed-phase clouds, which is significantly different from the subtropical marine boundary layer (MBL) clouds where warm liquid clouds are dominant (Dong et al., 2014; Wu et al., 2020; Zhao et al., 2020). Large biases in cloud amount and microphysics over the SO in the Coupled Model Intercomparison Project phase 5 (CMIP5) climate models result in a near $30 \mathrm{~W} \mathrm{~m}^{-2}$ shortwave radiation deficit at the top of the atmosphere (TOA) (Marchand et al., 2014; Stanfield et al., 2014, 2015), which further leads to unrealistic cloud

41 feedbacks and equilibrium climate sensitivity (Bony et al., 2015; Stocker et al., 2013). Meanwhile,

42 the efficiency of aerosol-cloud interaction (ACI) over the SO was found to be crucial for the

43 models' sensitivities to the radiation budget. A new aerosol scheme in the Hadley Centre Global

44 Environmental model can dampen the ACI and suppress negative clear-sky shortwave feedback,

45 both of which contribute to a larger climate sensitivity (Bodas-Salcedo et a., 2019). 
46 A climate sensitivity study using CMIP6 general circulation models (GCMs) shows much higher temperature variations across 27 GCMs in response to doubled $\mathrm{CO}_{2}$ than those in CMIP5, which may have resulted from the decreased extratropical low-level cloud cover and cloud albedo over the SO in CMIP6 (Zelinka et al., 2020). Low-level clouds are a key climate uncertainty and can explain $50 \%$ of the inter-model variations (Klein et al., 2017) because conversion from liquid cloud droplets to ice cloud particles decreases the cloud albedo and reduces the reflected shortwave radiation at TOA. Models, however, have difficulties accurately partitioning the cloud phase (Kalesse et al., 2016). The phase changes in mixed-phase clouds over the Arctic have proved to affect the cloud lifetime and radiative properties significantly, that is, converting from ice cloud particles to liquid cloud droplets may increase the cloud optical depth and the reflected shortwave radiation at TOA (Morrison et al., 2012). In contrast, models that allow mixed-phase clouds to glaciate rapidly can produce $30 \%$ more warming from doubling $\mathrm{CO}_{2}\left(\mathrm{McCoy}_{\mathrm{c}}\right.$ et al., 2014).

Phase transition processes have been investigated by several groups using both satellite and ground-based measurements. A study (Mace and Protat, 2018) found that there are more mixedphase clouds over the SO measured from the ship than retrieved from CloudSat and CALIPSO measurements because the satellites cannot accurately measure clouds below $\sim 1 \mathrm{~km}$. A previous study (Lang et al., 2018) used a model to investigate the clouds under post cold frontal systems and found large biases in model simulations and concluded that the cloud cover and radiative biases over the SO are highly regime dependent. Of all cloud types, low-level clouds are primarily responsible for the biases in the model simulations due to the lack of reliable measurements, which leads to a poor understanding of the conditions where these clouds form and the phase(s) that result. In other words, a physical representation of clouds, especially for low-level clouds, is unclear but 
macro- and micro-physical properties from ground-based active and passive remote sensors are crucial for the improvement of model simulations.

Previous studies show that cloud phase is primarily dependent on cloud temperature, and the transition from one cloud phase to another will modify the cloud optical properties, which further affects the radiation budgets (Hu et al., 2010; Intrieri et al., 2002; Morrison et al., 2012). Based on satellite observations and retrievals, they found that supercooled liquid water (SLW) clouds are most common in the low-level clouds over the SO, where $80 \%$ of low-level clouds contain SLW in a wide range of cloud temperatures from $0^{\circ} \mathrm{C}$ to $-40^{\circ} \mathrm{C}$ (Hu et al., 2010). The formation of SLW clouds is usually related to strong boundary layer convection. However, when ice nuclei exist in the mixed-phase clouds, the ice particles can grow quickly and become bigger through consuming supercooled liquid water drops. The SLW is inherently unstable due to the higher vapor pressure over liquid than over ice and the quicker vapor deposition on ice particles than on liquid droplets (Intrieri et al., 2002). As the supercooled liquid cloud droplets glaciate to ice particles, the cloud layer becomes darker because the ice particles scatter less shortwave radiation and absorb more radiation in the near IR wavelength regime. It is unclear, however, what role these ice particles play in the low-level clouds over the SO, which includes the impact on drizzle development. During HIAPER Pole-to-Pole Observation (HIPPO) campaigns, the study in Chubb et al. (2013) found that there are rarely ice particles in non-drizzling and light drizzling clouds over the SO, which may imply that the ice particles in the mixed-phase clouds may modulate the drizzle formation.

To investigate the aerosol and cloud properties over the SO, a field campaign called the Measurements of Aerosols, Radiation, and Clouds over the Southern Ocean (MARCUS) was 
92 the period October 2017-March 2018. The Department of Energy (DOE) Atmospheric Radiation

93 Measurement (ARM) Mobile Facility (AMF2) was installed on the Australian icebreaker Aurora

94 Australis, which voyaged from Hobart, Tasmania to the Australian Antarctic stations of Casey,

95 Mawson, and Davis, as well as Macquarie Island as illustrated in Fig. 1. Another field campaign,

96 called South Ocean Clouds, Radiation, Aerosol Transport Experimental Study (SOCRATES) field

97 campaign was conducted during austral summer from January 15 to February 26, 2018, which in-

98 situ measurements may use as a reference for this analysis. The SOCRATES domain has shown

99 as black dotted rectangle box in Fig. 1. The objectives of the MARCUS campaign are to investigate

100 the vertical distribution of boundary layer clouds and reveal the reasons why the mixed-phase

101 clouds are common in the warm season (McFarquhar et al., 2016), which will be our focuses for

102 this study.

103 MARCUS ship-based instruments include AMF2 cloud radar, lidar, microwave radiometer,

104 micropulse lidar, radiosonde sounding, precision solar pyranometer and precision infrared

105 radiometer, as well as aerosol sensors. Through these comprehensive observations over the SO,

106 we are tentatively answering the following three scientific questions:

107 (1) What is the total cloud fraction over the SO during MARCUS, as well as vertical 108 and meridional variations in cloud fraction?

109 (2) What are the dominant cloud types over the SO, their associated cloud properties, $110 \quad$ as well as their vertical and meridional distributions?

111 (3) What are the vertical and meridional distributions of the low-level clouds over the 112 SO? 
113 This manuscript is organized as follows: the data and method are introduced in section 2 . The

114 statistical results for all clouds during MARCUS are summarized in section 3. The low-level cloud

115 properties are described in section 4, followed by a summary and conclusions in section 5 .

\section{Data and Method}

The cloud properties analyzed in this study are derived from the data collected by AMF2, including the $95-\mathrm{GHz} \mathrm{W}-$ band cloud radar, ceilometer, micropulse lidar, microwave radiometer, aerosol observation system (AOS), meteorological measurements (MET, includes the following data: temperature, pressure, specific humidity, wind direction, and speed) on the ship, rain gauge and the radiosonde soundings. The combined cloud radar and ceilometer measurements can provide the cloud boundaries as long as there are no optically thin clouds and the cloud-base heights $\left(H_{\text {base }}\right)$ are not greater than the upper limit $(7.7 \mathrm{~km})$ of the ceilometer. The micropulse lidar will be used to identify optically thin clouds and the clouds with $H_{\text {base }}>7.7 \mathrm{~km}$. A previous study has shown that these additional clouds detected by the micropulse lidar can be a non-negligible supplement to the total cloud fraction (Mace et al., 2021). There are about 4 to 5 radiosonde soundings per day. We adopted a linear interpolation method based on these daily soundings to achieve a better temporal resolution of temperature, pressure, and specific humidity. The method considers MET measurements to ensure vertical continuity and adjacent soundings for temporal continuity. Using these interpolated atmospheric profiles, cloud temperatures can be accurately estimated.

133 The cloud occurrence frequency can be determined through two steps: the column cloud 134 fraction is simply the ratio of cloudy samples to the total observations in every 5-min; the 
136 number where column cloud fraction is greater than zero to the total 5-min samples. The cloud

137 liquid water path $(L W P)$ and atmospheric precipitable water vapor $(P W V)$ are retrieved based on a 138 physical-iterative algorithm using observations of the microwave radiometer brightness 139 temperature at 23.8 and $31.4 \mathrm{GHz}$ with uncertainties ranging from 15 to $30 \mathrm{~g} \mathrm{~m}^{-2}$ (Marchand et al., 140 2003). It is important to note that the brightness temperature biases switch signs among different 141 climatological regions because a threshold of $5{ }^{\circ} \mathrm{C}$ in cloud-base temperature was used in their 142 physical retrievals. Therefore, we propose an extra step to determine the uncertainties during 143 MARCUS. Both the AOS and rain gauge measurements were used to determine whether rain is 144 reaching the surface qualitatively, but not quantitatively in this study. All the measurements were averaged over 5 minutes except radar reflectivity, Doppler velocity, and spectrum width used in

146 Section 4.3. The detailed classification method will be introduced in Section 4.1. In brief, we used 147 the measurements of interpolated sounding, microwave radiometer retrieved $L W P$, radar 148 reflectivity, Doppler velocity and spectrum width to classify the cloud phase in each radar range 149 volume of low-level clouds during MARCUS. We also used ERA5 reanalysis data to study the environmental conditions during MARCUS and calculated the lower tropospheric stability (LTS) and estimated inversion strength (EIS) when the low-level clouds appeared along the shiptracks.

A classification method developed in Xi et al. (2010) was used to calculate the occurrence 153 frequencies of different types of clouds and their corresponding cloud macrophysical properties, 154 e.g., cloud base $\left(H_{\text {base }}\right)$ and top $\left(H_{\text {top }}\right)$ heights, cloud thickness $(\Delta H)$, and $L W P$. The relative 155 contributions of mixed-phase, liquid and ice clouds to the single-layered low-level clouds as well 156 as their drizzling status are analyzed in this study. To further investigate the drizzling status under 157 different cloud phases, we also calculated their LTS and EIS. The latitudinal and longitudinal 
variations of the single-layered low-level clouds as well as their vertical distributions are also explored in this study.

\section{Statistical results for all clouds during MARCUS}

The occurrence frequencies of total cloud cover and different types of clouds and their associated properties over the entire study domain during MARCUS are presented in Figs. 2-4. In order to examine the cloud properties over the mid-latitude and Polar regions, we separate the SO domain into northern (NSO, north of $60^{\circ} \mathrm{S}$ ) and southern ( $\mathrm{SSO}$, south of $60^{\circ} \mathrm{S}$ ) parts using a demarcation line of $60^{\circ} \mathrm{S}$. A total of 2,447 hours cloud samples were collected during MARCUS in this study, in which 1,181 hours of samples were located in the NSO and 1,266 hours of samples were collected from the SSO. It is important to note that adding micropulse lidar measurements increased the total samples of non-liquid-containing clouds by $\sim 20 \%$ because micropulse lidar is more sensitive to optically thin clouds than cloud radar. However, micropulse lidar signals are usually attenuated and cannot provide a meaningful signal when the liquid cloud layer is thicker than a couple of hundred meters (Sassen, 1991).

Figure 2 shows the vertical distributions of total cloud cover over the entire domain, as well as over NSO and SSO. For the vertical distributions, the occurrence frequencies of total cloud increase from the first radar gate $(\sim 226 \mathrm{~m})$ to $\sim 700 \mathrm{~m}$, then monotonically decrease with altitude with a few small increments at different levels, especially over SSO. We can draw the following conclusions by comparing the occurrence frequencies of the total cloud between NSO and SSO. 1) The SSO has more cloudiness than the NSO under $7 \mathrm{~km}$, while the NSO has more cloudiness than the SSO above $7 \mathrm{~km}$. 2) Below $3 \mathrm{~km}$, the occurrence frequencies of clouds over the NSO decrease dramatically from $37 \%$ at an altitude of $\sim 700 \mathrm{~m}$ to $16 \%$ at $3 \mathrm{~km}$ and from $45 \%$ to $28 \%$ over the 
181 SSO, which is similar to the vertical distributions of the low-level clouds over some Northern Hemisphere mid-latitude regions, such as Eastern North Atlantic (ENA, Dong et al., 2014). The occurrence frequencies measured during MARCUS are much lower than these shown in Fig. 8 of Mace et al. (2009) throughout the entire vertical column between the same range of latitudes, especially, the occurrence frequencies during MARCUS are almost half of these measured by CloudSat and CALIPSO from 1 to $3 \mathrm{~km}$. The reason has been explained in Xi et al. (2010), that is, a comparison of occurrence frequencies between measurements of two different platforms can only be performed under an equivalent spatial-to-temporal resolution. In other words, our results were calculated under 5-min temporal resolution, and the results in Mace et al. (2009) were statistically in the $2^{\circ}$ grid box. Therefore, the comparison between these two results is not reasonable. To make a fair comparison, one has to know the cloud amount at each area or time step, then the product of amount and frequency is independent of either temporal and spatial measurement.

To compare with other studies, we calculated the cloud fractions $(C F \mathrm{~s})$ of total and different types of clouds. The total $C F$ s were $77.9 \%, 67.6 \%$, and $90.3 \%$ for the entire domain, NSO and SSO, respectively, indicating that $22.7 \%$ more clouds occurred in the Polar region than in the midlatitude region. The total $C F$ over the entire domain is very close to the $76 \%$ calculated by Mace and Protat (2018) using ship-based measurements during the Cloud, Aerosols, Precipitation, Radiation and Atmospheric Composition (CAPRICORN) field experiment. The total $C F$ over the SSO is very close to that estimated by using the complementarity of CALIOP lidar aboard CALIPSO and CPR aboard CloudSat (DARDAR version 2 data) from Listowski et al. (2019).

Figure 3 shows the occurrence frequencies of categorized clouds and their cloud boundaries

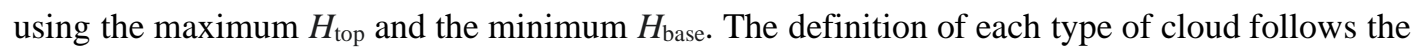


method of Xi et al. (2010). A brief description of the classification of cloud types is as follows.

The single-layered low-level clouds (LOW) is the fraction of time when low clouds with $H_{\text {top }} \leq 3$ $\mathrm{km}$ occur without clouds above them. Middle clouds (MID) range from 3 to $6 \mathrm{~km}$ without any clouds below and above, while high clouds (HGH) have $H_{\text {base }}>6 \mathrm{~km}$ with no cloud underneath. Other types of clouds are defined by different combinations of the above three types, middle over low (MOL), high over low (HOL), high over mid (HOM), and the cloud column through the entire troposphere is defined as HML. Three types, MOL, HOM, and HML, include both contiguous and non-contiguous cloud layers, and their thicknesses may be overestimated when clear layer(s) are present between any two cloud layers.

As illustrated in Fig. 3a, the single-layered low-level (LOW), deep cumulus or multi-layered (HML), and shallow cumulus (MOL) clouds are the three dominant types of clouds over the SO. Comparing the clouds between NSO and SSO, all types of clouds in SSO are higher than those in NSO except HOL. The differences range from less than $1 \%$ (LOW) to more than $10 \%$ (MOL). and ARM ENA site (Dong et al., 2014), we find: (1) The total cloud fractions (CFs) are close to each other (67.6 \% over NSO vs. $70.1 \%$ at ARM ENA); (2) LOW CFs are $22.9 \%$ vs. $27.1 \%$, which is the dominant type of cloud in both regions; and (3) Both MOL and HML clouds, including underneath low clouds, are $14.2 \%$ and $16.5 \%$ over NSO, much higher than those $(4.2 \%$ and $12.1 \%)$ at ARM ENA site, indicating that there are more shallow and deep convective clouds over NSO than over ENA.

Figure $3 \mathrm{~b}$ shows the vertical locations of different types of cloud layers, which represent the maximum $H_{\text {top }}$ and minimum $H_{\text {base }}$, as well as their deepest $\Delta H$ for any type of cloud. Nearly all 
solar radiation and stronger convection over NSO. $H_{\text {base }}$ values basically followed their cloud-top counterparts with a couple of exceptions. These cloud properties are closely associated with largescale dynamic patterns and environmental conditions. By analyzing the ERA-I reanalysis (not shown), the $850 \mathrm{hPa}$ geopotential heights show persistent westerlies with slightly higher geopotential heights over the northwest corner of the domain, which may closely relate to the higher $H_{\text {top }}$ over NSO than over SSO. Furthermore, the boundary layer over NSO is relatively more stable than over SSO based on lower troposphere stability analysis.

When we plot the probability density functions (PDFs) of cloud LWPs for different types of clouds, we find that the PDFs of $L W P$ s for HGH and HOM peak at less than $10 \mathrm{~g} \mathrm{~m}^{-2}$. These results make physical sense because HGH clouds should not contain any liquid droplets, and most HOM clouds, especially those over SSO, should be ice phase dominant. In addition, the $10 \mathrm{~g} \mathrm{~m}^{-2}$ of $L W P$ is close to the uncertainty of the LWP retrieval in Marchand et al. (2003). Therefore, this value is used as a threshold for all types of clouds, which leads to less than one percent reduction of the total samples. As shown in Fig. 4a, the LWPs $\left(>10 \mathrm{~g} \mathrm{~m}^{-2}\right)$ for all types of clouds are much higher over NSO than over SSO because the low-level and shallow convective clouds in the mid-latitudes contain more liquid water than those in Polar regions. The mean $L W P$ s for liquid containing lowlevel and middle-level clouds over NSO, such as LOW, MID and HOL, range from 130 to $150 \mathrm{~g}$ $\mathrm{m}^{-2}$, while the mean $L W P$ s for shallow and deep convective clouds, such as MOL and HML, are two times higher $\left(\sim 270 \mathrm{~g} \mathrm{~m}^{-2}\right)$ than the mean $L W P$ of LOW, MID and HOL. Note that the mean LWPs for most types of clouds over the SSO are much lower than those over the NSO, except for the LOW clouds.

Table 1 provides a summary of the average, standard derivation, minimum and maximum for 
over the SO. Non-contiguous clouds over the SO occur very frequently, especially for HOM and

HML. The $L W P$ for single-layered clouds is greater than that for multi-layered clouds. The $L W P$ for single-layered HML almost doubles that for multi-layered HML.

The occurrence frequencies of $L W P \mathrm{~s}\left(>10 \mathrm{~g} \mathrm{~m}^{-2}\right)$ over NSO and SSO contradict their cloud LWP counterparts, as demonstrated in Fig. 4b. To further investigate the amount of available precipitable water vapor $(P W V)$, we found that mean $P W V$ values in SSO are at least 2 to 3 times less than those in NSO for the same types of clouds (figure not shown). Note that the samples of MID, HGH, and HOM clouds are excluded from this study when they have LWPs less than $10 \mathrm{~g}$ $\mathrm{m}^{-2}$, since these low $L W P$ s are within the retrieval uncertainty of cloud $L W P$ and hence may not contain any liquid cloud droplets. The higher $L W P$ s, larger cloud droplets, drizzle drops and ice particles, and greater drizzling occurrence frequencies over NSO (which is discussed later) will lead to the quick dissipation of clouds over NSO. In contrast to NSO, the SSO cloud LWPs and particle sizes are much smaller with fewer drizzling events, which increases cloud lifetime relative to NSO. The $67.6 \%$ and $90.3 \% C F$ s over NSO and SSO provide strong evidence for this argument. We can draw the following conclusions by comparing the cloud properties between NSO and SSO in Figs. 3 and 4. The LOW fraction, thickness, and LWP over NSO and SSO are comparable to each other. For other types of clouds, cloud thicknesses are similar to each other or slightly deeper over NSO, but the cloud $L W P$ s over NSO are much larger than those over SSO, resulting in more precipitation events over NSO. As pointed out in (Albrecht 1989), more precipitation events may reduce the cloud lifetime. This argument is consistent with the results shown in Figs. 2 and 3a for all clouds except for HOL. Cloud lifetimes over NSO are shorter than those over SSO, which leads to lower $C F$ s over NSO than over SSO. 


\section{Single-layered low-level clouds}

As discussed in Section 3, single-layered low-level clouds (LOW) are the dominant cloud type in both northern (NSO) and southern (SSO) parts of the SO. Figs. 3 and 4 further reveal that LOW cloud type is the only one having comparable $C F$, cloud, thickness, $L W P$ over both NSO and SSO. This warrants further study: Are the cloud phases, properties, and vertical and meridional variations of LOW clouds over these two regions similar to each other or significantly different?

\subsection{Cloud phase}

In this study, cloud boundaries are determined by combining cloud radar, ceilometer and micropulse lidar measurements at a temporal resolution of 5-min. The cloud phase, liquid water droplets or ice particles, are determined in each radar range volume. A flow chart for classifying the phases of single-layered low-level clouds is drawn in Fig. 5. The determination of warm liquid clouds is straightforward using both cloud-base ( $\left.T_{\text {base }}\right)$ and -top $\left(T_{\text {top }}\right)$ temperatures greater than 0 ${ }^{\circ} \mathrm{C}$, and cloud $L W P$ s greater than the threshold $\left(10 \mathrm{~g} \mathrm{~m}^{-2}\right)$. The determination of supercooled liquid clouds is slightly complicated. When either $T_{\text {base }}$ or $T_{\text {top }}$ is below $0^{\circ} \mathrm{C}$, and cloud $L W P$ s are greater than the threshold, the radar Doppler spectrum width $(W I D)$ and velocity $\left(V_{\mathrm{d}}\right)$ are used for the determination of supercooled liquid water clouds. If the majority (10 seconds of original radar measurements) of WID are less than $0.4 \mathrm{~m} \mathrm{~s}^{-1}$ and $V_{\mathrm{d}}$ are equal to or less than $0.0 \mathrm{~m} \mathrm{~s}^{-1}$ (updrafts) in the volume, then this range volume is defined as supercooled liquid clouds.

Mixed-phase clouds are determined when the medians (calculated from 10 seconds of original radar measurements) of WID is greater than $0.4 \mathrm{~m} \mathrm{~s}^{-1}$ and $V_{\mathrm{d}}$ is greater than $0.0 \mathrm{~m} \mathrm{~s}^{-1}$ (downdrafts) due to the existence of large ice particles in the clouds. If cloud $L W P$ is below the threshold, then

294 it is defined as an ice cloud, otherwise, it is defined as a mixed-phase cloud. It is worth mentioning that large ice particles, which grow through vapor deposition or rime processes, dominate the radar 
reflectivity and are heavier than cloud droplets. Therefore, these large ice particles not only broaden the spectrum width but also have relatively large fall speeds.

To further evaluate our classification method, we compared the classified mixed-phase and ice clouds with the micropulse lidar linear depolarization ratios $(L D R)$ as an extra measure. The $L D R$ ranges follow the method in Shupe et al. (2005), which are $0.11<L D R<0.15$ for mixed-phase clouds, and $L D R>0.15$ for ice clouds. Table 2a shows the quantitative comparison of the cloud phase identifications between these two classification methods. The numbers represent the counts of each matched 5-min sample, where the diagonal numbers indicate that both methods are identifying the same type of cloud phase. In general, the two methods have $89 \%$ agreement on the phase identification. Secondly, we performed the phase classification directly from microphysical probes onboard G-1 aircraft during SOCRATES and treated them as 'ground-truth' (Mohrmann et al., 2021). By changing the time step of sampling to mimic what the radar may observe the cloud for each range volume, Table $2 \mathrm{~b}$ shows the statistics of the possibility of the cloud phase that may be detected by cloud radar. As sampling time increases from 1 second to 30 seconds, more mixedphase clouds and fewer single-phase clouds can be observed.

Figure 6 shows the occurrence frequencies of the matched results for mixed-phase clouds (left panel) and ice clouds (right column). For the classified ice clouds, most of the Doppler spectrum widths range from 0.08 to $0.16 \mathrm{~m} \mathrm{~s}^{-1}$ and the $L D R$ ratios can be up to $\sim 0.5$, representing a narrow range of ice particle size distribution with higher $L D R$ ratios. Cloud liquid is identified by low $L D R$ of $\sim 0.11$ (Fig. $6 \mathrm{~d}$ ) and high lidar backscatter from $10^{-5}$ to $10^{-4} \mathrm{~m}^{-1} \mathrm{sr}^{-1}$ (Fig. 6e). For the classified mixed-phase clouds, most of the Doppler spectrum width range from 0.15 to $0.35 \mathrm{~m} \mathrm{~s}^{-1}$ and most

317 of the $L D R$ signals are less than 0.4 , representing a broad particle size distribution resulting from 
319 the mode values for both mixed-phase and ice clouds occur at $\sim 0.5 \mathrm{~m} \mathrm{~s}^{-1}$, where the ice particles are dominant in both types of clouds. The broader particle size distribution with lower $L D R$ ratios

321 for mixed-phase clouds and narrower particle size distribution with higher $L D R$ ratios for ice 322 clouds further corroborate that the classified results from this study are consistent with the traditional micropulse lidar $L D R$ method.

324 It is important to note that the micropulse lidar signals are usually attenuated and cannot provide a meaningful signal when the liquid cloud layer is thicker than a couple of hundred meters (Sassen, 1991). Arctic mixed-phase clouds are typical, with the liquid-dominant layer on the top of the mixed-phase clouds and the ice-dominant layer underneath. The ceilometer-derived cloudbase height represents the base of the liquid-dominant layer near the cloud top, while MPL-derived cloud-base height represents the base of the lower ice-dominant layer (Qiu et al., 2015; Shupe, 2007; Shupe et al., 2005). Over the Arctic, the micropulse lidar signals can penetrate through the ice-dominant layer to the liquid-dominant layer. However, the mixed-phase clouds over the Southern Ocean are totally different from those over the Arctic region: they are well mixed (liquid droplets and ice particles) from cloud base to cloud top, which is found in this study. Thus, the micropulse lidar signals can be attenuated in the mixed-phase clouds over the Southern Ocean. Statistical results show that $43 \%$ of micropulse data were attenuated during MARCUS compared to our classified results.

337 This classification method is further supported by the onboard cloud radar measurements 338 during the Southern Ocean Clouds Radiation Aerosol Transport Experimental Study (SOCRATES, 339 not shown). In that campaign, the reflectivity measurements were usually greater, and the spectrum 340 widths were much wider when the aircraft observed large ice particles compared to the time 341 periods when liquid cloud droplets were observed. It is also worth mentioning that about $5.5 \%$ of 
342 single-layered low-level cloud phases cannot be determined when the radar measurements were not available during MARCUS. Therefore, using our classification method, a total of 6,934 5-min single-layered low-level cloud samples were determined in this study, including 697 liquid cloud samples, 3,777 mixed, 1,205 ice, and 1,255 'OTHER' clouds. The category of 'OTHER' clouds represents more than one phase in each column. (yellow-green), virga (brown) and rain (navy blue). The definition of drizzling status follows the method in Wu et al., $(2015,2017)$, which used both ceilometer and cloud radar measurements to determine the status of MBL clouds under non-drizzling, virga and rain conditions. The percentages shown below the $\mathrm{x}$-axis represent the portion of drizzling status in each type of clouds, such as liquid, mixed-phase, ice and 'OTHER' clouds. Figure 7 (bottom panel) also shows the percentages and vertical distributions of classified liquid, mixed-phase, ice, and 'OTHER' clouds for each column in the single-layered low-level clouds, represented by different colors. After classification, the samples in each category are sorted by their $H_{\text {top. }}$ In detail, Fig. 7 demonstrates that the mixed-phase clouds dominate the single-layered low-level cloud category with an occurrence frequency of $54.5 \%$. The 'OTHER' and ice clouds have similar occurrence frequencies of $18.1 \%$ and $17.4 \%$, respectively, while the liquid clouds have the least occurrence frequency of $10.1 \%$. The liquid topped mixed-phase clouds (included in 'OTHER'), which frequently occur in the Arctic region (Qiu et al., 2015), are rarely found over the SO. The existence of ice particles in mixed-phase clouds should strongly depend on the distribution of ice nuclei (IN), whereas spatially unevenly distributed IN may result in the OTHER type of clouds.

363 Based on the results in Fig. 7, we draw the following conclusions. Most of the ice clouds are 
and $15 \%$, respectively. The percentages of non-drizzling, virga and drizzling mixed-phase clouds are $50 \%, 21 \%$, and $29 \%$. The liquid and 'OTHER' clouds have similar percentages, they are $36 \%$, $25 \%$ and $39 \%$ for liquid clouds, and $35 \%, 22 \%$ and $44 \%$ for 'OTHER' clouds. For liquid and 'OTHER' clouds, the drizzling frequencies are independent of $H_{\text {top. }}$ In contrast, for mixed-phase and ice clouds, the drizzling frequencies strongly depend on $H_{\text {top }}$, i.e., higher drizzling frequencies occur mostly at higher $H_{\text {top }}$. have the lowest $H_{\text {base }}$ and $H_{\text {top }}$ but more available water vapor than other types of clouds. Since the 'OTHER' clouds are a transitional stage among mixed-phase, liquid and ice clouds, they have the highest $H_{\text {top }}$, deepest cloud layer and largest $L W P$. The ice clouds occur in relatively dry environments and have the highest $H_{\text {base }}$ at $1.218 \mathrm{~km}$. The mixed-phase clouds have similar $H_{\text {base, }}$ but lower $H_{\mathrm{top}}, L W P$ and $P W V$ compared to those of 'OTHER' clouds. Since $L W P$ s in mixed-phase clouds have larger standard deviations, which implies that SLW is more common at higher LWPs and ice is more common at lower $L W P$ s.

\subsection{Meridional variations of cloud properties}

Figure 8 shows the meridional variation in single-layered low-level cloud properties during MARCUS. As illustrated in Fig. 8a, the meridional distributions of $H_{\text {base, }} H_{\text {top }}$ and $\Delta H$ are nearly independent of latitude, however, their corresponding temperatures ( $T_{\text {base }}$ and $\left.T_{\text {top }}\right)$ increased about $8 \mathrm{~K}$ from $69{ }^{\circ} \mathrm{S}$ to $43{ }^{\circ} \mathrm{S}$, though there were slight fluctuations. These results suggest that the cloud and sea surface temperatures have minimal impact on the cloud boundaries over the SO, which is consistent with the findings in McFarquhar et al. (2016). The meridional variation of $L W P$ s mimics those of $T_{\text {base }}$ and $T_{\text {top }}$, with an increasing trend from south to north. It is important to point out that 
that the cloud samples at some latitudes are not statistically significant. The atmospheric $P W V$ increased dramatically from $\sim 5 \mathrm{~mm}$ at $69^{\circ} \mathrm{S}$ to $\sim 18 \mathrm{~mm}$ at $43^{\circ} \mathrm{S}$, presumably due to increased sea surface and atmospheric temperatures.

Figure 9 shows the latitudinal and meridional distributions of categorized liquid, mixed-phase,

392 ice and 'OTHER' in single-layered low-level clouds over the SO during MARCUS. Each circle

393 represents the exact location and time along the ship track. Mixed-phase clouds occurred

394 everywhere over the SO during the MARCUS field campaign and became dominant in November,

395 December and February. Liquid clouds dominated in March, while ice clouds dominated in

January. The 'OTHER' clouds are a kind of transitional phase falling in between the mixed-phase and ice/liquid clouds because there are no stand-alone occurrences in any month during MARCUS.

\subsection{Vertical distribution of cloud properties}

The vertical distributions of classified liquid, mixed-phase, and ice clouds are presented in Figs.

10-12. The focus of this section will be comparisons of cloud properties between the north (NSO) and south (SSO) regions of the domain. Figure 10a shows the vertical distributions of liquid clouds, which were capped at $\sim 1.6 \mathrm{~km}$, mostly in the marine boundary layer. The vertical occurrence frequencies are up to $27 \%$ over NSO, while they were less than $4 \%$ over SSO, i.e., liquid clouds occurred fairly often over the mid-latitude region, but very few occurred over the Polar region. On the contrary, the occurrence frequencies of mixed-phase clouds between NSO and SSO are opposite to liquid clouds, as illustrated in Fig. 10b, though the differences are not so obvious.

407 Mixed-phase clouds increased with altitude until $\sim 1.6 \mathrm{~km}$, then decreased monotonically towards $4083 \mathrm{~km}$. The highest frequencies were $\sim 37 \%$ at $0.6 \mathrm{~km}$ over SSO and $\sim 27 \%$ at $1.5 \mathrm{~km}$ over NSO. 409 The vertical distributions of ice clouds are similar to those of mixed-phase clouds (Fig. 10c). 410 However, there were no significant differences between NSO and SSO. It is worth mentioning that 
411 the vertical distributions of mixed-phased clouds over SO are quite different to those from DOE

412 ARM Northern Slope Alaska (NSA) site where the liquid topped mixed-phase low-level clouds 413 are common (e.g., Qiu et al., 2015).

414 To further investigate the vertical distributions of classified liquid, mixed-phase, and ice clouds 415 over NSO and SSO, we plot the normalized vertical distributions (cloud base as 0, cloud top as 1) 416 of radar reflectivity, Doppler velocity and spectrum width in Figs. 11 and 12, respectively. In this 417 study, the threshold of $-50 \mathrm{dBZ}$ was used to determine the cloud boundary over the SO instead of 418 the threshold of $-40 \mathrm{dBZ}$ radar reflectivity used at the ARM ENA site (Dong et al., 2014). If we 419 used the threshold of $-40 \mathrm{dBZ}$ over the SO, then there would be only $73 \%$ cloud samples available 420 for this study. About $9.6 \%$ of radar reflectivities during MARCUS are less than $-50 \mathrm{dBz}$ for all 421 single-layered low-level cloud samples. Thus all radar parameters used in this study are based on $42290.4 \%$ of the radar measurements with reflectivity greater than $-50 \mathrm{dBz}$.

423 Figures 11a-11c represent the normalized vertical distributions of radar reflectivity, Doppler velocity and spectrum width of liquid clouds. Liquid clouds had the lowest reflectivity near the cloud top because of cloud-top entrainment., The reflectivity had a nearly constant median value of $\sim-22 \mathrm{dBZ}$ from near cloud top height $(\sim 0.8$ for normalized height) of the cloud layer to the cloud base. Most of the reflectivities were less than $-15 \mathrm{dBz}$, which is the threshold to distinguish 428 cloud and drizzle-sized particles in each radar range volume (Wu et al., 2020). Most of the Doppler 429 velocities were greater than $0.0 \mathrm{~m} \mathrm{~s}^{-1}$, indicating that downwelling motion is dominant in liquid 430 clouds. The profiles of Doppler velocity and spectrum width increased smoothly from the cloud 431 top to base, suggesting that larger cloud droplets and broader size distributions exist near the cloud 432 base, which is attributable to more drizzle drops near the cloud base, as illustrated in Fig. 7. 

clouds. The more occurrences of larger reflectivity measurements and larger median values of spectrum width near the cloud base are most likely due to the presence of moderate ice particles and/or drizzle drops. The nearly same median values of reflectivity, Doppler velocity and spectrum width (but slightly larger standard deviations in each level in mixed-phase clouds) in both liquid and mixed-phase clouds suggest that the ice particle sizes in mixed-phase clouds are comparable to cloud droplets and drizzle drops. The nearly uniform vertical distributions of Doppler velocity and spectrum width indicate well-mixed liquid cloud droplets and ice particles throughout the cloud layer in the mixed-phase clouds over NSO.

Ice clouds had much lower reflectivity and narrower spectrum width than liquid and mixedphase clouds, as shown in Figs. 11g-11i. Almost all reflectivity measurements were less than -25 $\mathrm{dBz}$ with a median value of $-35 \mathrm{dBz}$ at the cloud base, resulting from small or moderate ice particles but much lower concentration. A nearly constant Doppler velocity within the cloud layer further supports the discussion of mixed-phase clouds above, i.e., the ice particle sizes are independent of cloud height and comparable to liquid cloud droplets in the low-level clouds over the SO. Because there are no mechanisms for growing large ice particles in such shallow ice clouds, the accretion process cannot take place. From the statistical results in Fig. 7, these ice particles have relatively little chance to become virga or raindrops and usually dissipate or transition to other types of clouds.

452 Since there are not enough liquid cloud samples over the Polar region, only the mixed-phase and ice clouds results are plotted in Fig. 12. Compared to the vertical distributions of ice clouds over NSO, the median values of reflectivity and Doppler spectrum width over SSO were lower 
the Polar region were also reflected in their mixed-phase clouds. Compared to the vertical distributions of the mixed-phased clouds over NSO, the median values of reflectivity and Doppler spectrum width over SSO were dramatically lower ( $-35 \mathrm{dBz}$ at SSO vs. $-22 \mathrm{dBz}$ at NSO; $0.25 \mathrm{~m}$ $\mathrm{s}^{-1}$ at SSO vs. $0.32 \mathrm{~m} \mathrm{~s}^{-1}$ at NSO). Figure 12 illustrates that the ice particle sizes over SSO are smaller, their size distributions are narrower than those over NSO, indicating of lack of large ice particles over SSO.

462

\section{Summary and Conclusions}

In this study, we presented the statistical results of clouds over the Southern Ocean (SO) and the northern (NSO) and southern (SSO) parts during MARCUS IOP. We used the method developed in Xi et al. (2010) to calculate the occurrence frequencies of different types of clouds and their corresponding cloud macrophysical properties. We developed a new method to classify liquid, mixed-phased, and ice clouds in the single-layered low-level clouds as well as their corresponding drizzling status. Lastly, we explored the meridional and vertical distributions of these classified cloud properties. Analysis of the MARCUS cloud properties has yielded the following conclusions.

1. The total cloud fractions $(C F \mathrm{~s})$ were $77.9 \%, 67.6 \%$, and $90.3 \%$ for the entire

473 domain, NSO and SSO, respectively, indicating that $22.7 \%$ more clouds occurred in the Polar 474 region than in the mid-latitude region. The SSO had more clouds under $7 \mathrm{~km}$, while the NSO 475 had more clouds above $7 \mathrm{~km}$. Below $3 \mathrm{~km}$, the occurrence frequencies of clouds over NSO 476 decrease dramatically from $37 \%$ at an altitude of $\sim 700 \mathrm{~m}$ to $16 \%$ at $3 \mathrm{~km}$, which is similar to 477 the vertical distributions of the low-level clouds over some Northern Hemisphere mid-latitude 478 regions, such as Eastern North Atlantic. 

shallow cumulus (MOL) clouds are the three dominant types of clouds over the SO. Comparing the clouds between NSO and SSO, all types of clouds in SSO are higher than those in NSO except HOL. The LOW fraction, thickness, LWP over both NSO and SSO are comparable to each other. The mean $L W P$ s for low clouds over NSO, such as LOW, MOL and HOL, range from $\sim 130$ to $150 \mathrm{~g} \mathrm{~m}^{-2}$, while the mean $L W P$ s for shallow and deep convective clouds, such as MOL and HML, are two times $\left(\sim 270 \mathrm{~g} \mathrm{~m}^{-2}\right)$ higher than the same types of clouds. The mean $L W P$ s of clouds over SSO are much lower than the LWPs over NSO. Over the Southern Ocean, the single-layered or contiguous clouds usually have higher liquid water paths than their counterpart of multi-layered or non-contiguous clouds. There are more non-contiguous HML and HOM than contiguous ones.

3. A new method was developed to classify liquid, mixed-phase and ice clouds in the single-layered low-level clouds (LOW) based on comprehensive ground-based observations. The mixed-phase clouds are dominant in the single-layered low-level cloud category with an occurrence frequency of $54.5 \%$. The 'OTHER' and ice clouds had similar occurrence frequencies of $18.1 \%$ and $17.4 \%$, respectively, while the liquid clouds had the least occurrence frequency of $10.1 \%$. The percentages of non-drizzling, virga and drizzling for mixed-phase clouds were $50 \%, 21 \%$, and $29 \%$, and the drizzling frequencies of mixed-phase clouds strongly depend on $\mathrm{H}_{\text {top }}$, that is, higher drizzling frequencies occurred mostly at higher $H_{\text {top }}$.

4. The meridional distributions of $H_{\text {base }}, H_{\text {top }}$ and $\Delta H$ are nearly independent on latitude. However, their corresponding temperatures increased about $8 \mathrm{~K}$ from $69{ }^{\circ} \mathrm{S}$ to $43{ }^{\circ} \mathrm{S}$. The meridional variation of $L W P$ s mimics that of cloud temperatures, having an increasing trend from south to north. The mean $P W V$ increased dramatically from $\sim 5 \mathrm{~mm}$ at $69{ }^{\circ} \mathrm{S}$ to $\sim 18$ 
$\mathrm{mm}$ at $43{ }^{\circ} \mathrm{S}$ due to increased sea surface and atmospheric temperatures. More liquid clouds occurred over NSO but very few occurred over SSO, whereas more mixed-phase clouds occurred over SSO than over NSO. There were no significant differences in ice clouds occurrences between NSO and SSO.

5. The nearly same median values of reflectivity, Doppler velocity and spectrum width in both liquid and mixed-phase clouds over NSO suggest that the ice particle sizes in mixed-phase clouds are comparable to cloud droplets and drizzle drops. The uniform vertical distributions of Doppler velocity and spectrum width suggest well-mixed liquid cloud droplets and ice particles throughout the cloud layer in the mixed-phase clouds over NSO, which are quite different from those over the DOE ARM NSA site where the liquid topped mixed-phase MARCUS, including the occurrence frequencies of different types of clouds and their corresponding cloud macrophysical properties. We also examined the meridional and vertical distributions of the classified cloud properties. These statistics can be used as ground truth to evaluate satellite retrieved cloud properties and model simulations over the SO. The results of this study will help to advance our understanding of these clouds, which may lead to improved model simulations over the $\mathrm{SO}$ as well as a better representation of global climate. 
Author contributions. The idea of this study is discussed by BX, XD, and XZ. BX and XZ performed

527 the analyses and BX wrote the manuscript. BX, XD, XZ and PW participated in scientific discussions

528 and provided substantial comments and edits on the paper.

529

530 Competing interests. The authors declare that they have no conflict of interest.

531

532 Acknowledgements. The ground-based measurements were obtained from the Atmospheric 533 Radiation Measurement (ARM) Program sponsored by the U.S. Department of Energy (DOE) 534 Office of Energy Research, Office of Health and Environmental Research, and Environmental 535 Sciences Division. The data can be downloaded from http://www.archive.arm.gov/. Researchers were supported by the NSF project under grant AGS-2031750 at the University of Arizona. Specially thanks to Mr. Xingyu Zhang for providing analysis from CDP and 2DS microphysical sensors during SOCRATES and Dr. Dale Ward at the University of Arizona for proofreading this manuscript.

References.

Albrecht, B. A.: Aerosols, cloud microphysics, and fractional cloudiness, Science, doi:10.1126/science.245.4923.1227, 1989.

Bodas-Salcedo, A., Mulcahy, J. P., Andrews, T., Williams, K. D., Ringer, M. A., Field, P. R. and Elsaesser, G. S.: Strong Dependence of Atmospheric Feedbacks on Mixed-Phase Microphysics and Aerosol-Cloud Interactions in HadGEM3, J. Adv. Model. Earth Syst., 
Bony, S., Stevens, B., Frierson, D. M. W., Jakob, C., Kageyama, M., Pincus, R., Shepherd, T. G., Sherwood, S. C., Siebesma, A. P., Sobel, A. H., Watanabe, M. and Webb, M. J.: Clouds, circulation and climate sensitivity, Nat. Geosci., doi:10.1038/ngeo2398, 2015.

Chubb, T. H., Jensen, J. B., Siems, S. T. and Manton, M. J.: In situ observations of supercooled liquid clouds over the Southern Ocean during the HIAPER Pole-to-Pole Observation campaigns, Geophys. Res. Lett., doi:10.1002/grl.50986, 2013.

Dong, X., Xi, B., Kennedy, A., Minnis, P. and Wood, R.: A 19-month record of marine aerosolcloud-radiation properties derived from DOE ARM mobile facility deployment at the Azores. Part I: Cloud fraction and single-layered MBL cloud properties, J. Clim., doi:10.1175/JCLI-D-13-00553.1, 2014.

Hu, Y., Rodier, S., Xu, K. M., Sun, W., Huang, J., Lin, B., Zhai, P. and Josset, D.: Occurrence, liquid water content, and fraction of supercooled water clouds from combined

Intrieri, J. M., Fairall, C. W., Shupe, M. D., Persson, P. O. G., Andreas, E. L., Guest, P. S. and Moritz, R. E.: An annual cycle of Arctic surface cloud forcing at SHEBA, J. Geophys. Res. Ocean., doi:10.1029/2000jc000439, 2002.

Kalesse, H., de Boer, G., Solomon, A., Oue, M., Ahlgrimm, M., Zhang, D., Shupe, M. D., Luke, E. and Protat, A.: Understanding rapid changes in phase partitioning between cloud liquid and ice in stratiform mixed-phase clouds: An arctic case study, Mon. Weather Rev., doi:10.1175/MWR-D-16-0155.1, 2016. 
Lang, F., Huang, Y., Siems, S. T. and Manton, M. J.: Characteristics of the Marine Atmospheric Boundary Layer Over the Southern Ocean in Response to the Synoptic Forcing, J. Geophys. Res. Atmos., doi:10.1029/2018JD028700, 2018.

Listowski, C., Delanoë, J., Kirchgaessner, A., Lachlan-Cope, T. and King, J.: Antarctic clouds, supercooled liquid water and mixed phase, investigated with DARDAR: Geographical and seasonal variations, Atmos. Chem. Phys., doi:10.5194/acp-19-6771-2019, 2019.

Mace, G. G., Zhang, Q., Vaughan, M., Marchand, R., Stephens, G., Trepte, C. and Winker, D.: A description of hydrometeor layer occurrence statistics derived from the first year of merged Cloudsat and CALIPSO data, J. Geophys. Res. Atmos., doi:10.1029/2007JD009755, 2009.

Mace, G. G. J. and Protat, A.: Clouds over the Southern Ocean as observed from the R/V investigator during CAPRICORN. Part I: Cloud occurrence and phase partitioning, J. Appl. Meteorol. Climatol., doi:10.1175/JAMC-D-17-0194.1, 2018.

Mace, G. G., Protat, A., Humphries, R. S., Alexander, S. P., McRobert, I. M., Ward, J., Selleck, P., Keywood, M. and McFarquhar, G. M.: Southern Ocean Cloud Properties Derived From CAPRICORN and MARCUS Data, J. Geophys. Res. Atmos., doi:10.1029/2020JD033368, 2021.

Marchand, R., Ackerman, T., Westwater, E. R., Clough, S. A., Cady-Pereira, K. and Liljegren, J. C.: An assessment of microwave absorption models and retrievals of cloud liquid water using clear-sky data, J. Geophys. Res. Atmos., doi:10.1029/2003jd003843, 2003.

Marchand, R., Wood, R., Bretherton, C., McFarquhar, G., Protat, A., Quinn, P., Siems, S., Jakob, C., Alexander, S., Weller, B.: The Southern Ocean Clouds, Radiation Aerosol Transport 
4.pdf, 2014.

Mccoy, D. T., Hartmann, D. L. and Grosvenor, D. P.: Observed Southern Ocean cloud properties and shortwave reflection. Part II: Phase changes and low cloud feedback, J. Clim., doi:10.1175/JCLI-D-14-00288.1, 2014.

McFarquhar, G., Bretherton, C., Alexander, S., DeMott, P., Marchand, R., Protat, A., Quinn, P., Siems, S., Weller, R., Wood, R.: Measurements of Aerosols, Radiation, and Clouds over Sothern Ocean (MARCUS) Science Plan, DOE ARM Climate Research Facility., DOE/SC-ARM-16-011, available at: http://arm.gov/publications/programdocs/doe-sc-

605 arm-16-011.pdf, 2016.

Mohrmann, J., Finlon, J., Atlas, R., Lu, J., Hsiao, I., Wood, R.: University of Washington IceLiquid Discriminator single particle phase classifications and $1 \mathrm{~Hz}$ particle size distributions/heterogeneity estimate, Version 1.0. UCAR/NCAR - Earth Observing Laboratory., doi:10.26023/PA5W-4DRX-W50A, Last Access: Nov 01, 2021

Morrison, H., De Boer, G., Feingold, G., Harrington, J., Shupe, M. D. and Sulia, K.: Resilience of persistent Arctic mixed-phase clouds, Nat. Geosci., doi:10.1038/ngeo1332, 2012.

Qiu, S., Dong, X., Xi, B. and Li, J. L. F.: Characterizing Arctic mixed-phase cloud structure and its relationship with humidity and temperature inversion using ARM NSA observations, J. Geophys. Res., doi:10.1002/2014JD023022, 2015.

Sassen, K.: The polarization lidar technique for cloud research: a review and current assessment, Bull. - Am. Meteorol. Soc., doi:10.1175/1520-0477(1991)072<1848:TPLTFC>2.0.CO;2, 1991.

Shupe, M. D., Uttal, T. and Matrosov, S. Y.: Arctic cloud microphysics retrievals from surfacebased remote sensors at SHEBA, J. Appl. Meteorol., doi:10.1175/JAM2297.1, 2005. 
619 Shupe, M.: A ground-based multisensory cloud phase classifier, Geophys. Res. Lett., doi:10.1029/2007GL031008, 2007.

621 Stanfield, R. E., Dong, X., Xi, B., Kennedy, A., Del Genio, A. D., Minnis, P. and Jiang, J. H.: Assessment of NASA GISS CMIP5 and Post-CMIP5 Simulated Clouds and TOA Radiation Budgets Using Satellite Observations. Part I: Cloud Fraction and Properties, J. Clim., doi:10.1175/jcli-d-13-00558.1, 2014. Assessment of NASA GISS CMIP5 and post-CMIP5 simulated clouds and TOA radiation budgets using satellite observations. Part II: TOA radiation budget and CREs, J. Clim., doi:10.1175/JCLI-D-14-00249.1, 2015.

Stocker, T. F., Qin, D., Plattner, G. K., Tignor, M. M. B., Allen, S. K., Boschung, J., Nauels, A., Xia, Y., Bex, V. and Midgley, P. M.: Climate change 2013 the physical science basis:

Wu, P., Dong, X. and Xi, B.: Marine boundary layer drizzle properties and their impact on cloud property retrieval, Atmos. Meas. Tech., doi:10.5194/amt-8-3555-2015, 2015.

Wu, P., Dong, X., Xi, B., Liu, Y., Thieman, M. and Minnis, P.: Effects of environment forcing on marine boundary layer cloud-drizzle processes, J. Geophys. Res., doi:10.1002/2016JD026326, 2017. 0272.1, 2020. 
641 Xi, B., Dong, X., Minnis, P. and Khaiyer, M. M.: A 10 year climatology of cloud fraction and vertical distribution derived from both surface and GOES observations over the DOE ARM SPG site, J. Geophys. Res. Atmos., doi:10.1029/2009JD012800, 2010.

644 Zelinka, M. D., Myers, T. A., McCoy, D. T., Po-Chedley, S., Caldwell, P. M., Ceppi, P., Klein, S. A. and Taylor, K. E.: Causes of Higher Climate Sensitivity in CMIP6 Models, Geophys. Res. Lett., doi:10.1029/2019GL085782, 2020.

647 Zhao, L., Zhao, C., Wang, Y., Wang, Y. and Yang, Y.: Evaluation of Cloud Microphysical Properties Derived From MODIS and Himawari-8 Using In Situ Aircraft Measurements Over the Southern Ocean, Earth Sp. Sci., doi:10.1029/2020EA001137, 2020. 
Table 1. Minimum cloud base heights $\left(H_{\text {base }}\right)$, maximum cloud top heights $\left(H_{t o p}\right)$, and liquid water paths $(L W P$ s) (all samples, single-layered, multilayered) of all seven types of clouds over the Southern Ocean. Cloud heights have unit of kilometer, and $L W P$ has unit of $\mathrm{g} \mathrm{m}^{-2}$.

\begin{tabular}{|c|c|c|c|c|c|c|c|}
\hline & LOW & MID & MOL & HGH & HOM & HML & HOL \\
\hline $\begin{array}{c}\boldsymbol{H}_{\text {base }} \pm \text { std } \\
\text { min, max }\end{array}$ & $\begin{array}{c}0.92 \pm 0.57 \\
0.06,2.86\end{array}$ & $\begin{array}{c}4.14 \pm 0.61 \\
3.00,5.84\end{array}$ & $\begin{array}{c}1.37 \pm 0.96 \\
0.06,5.27\end{array}$ & $\begin{array}{l}8.51 \pm 2.23 \\
6.00,18.67\end{array}$ & $\begin{array}{c}4.70 \pm 0.80 \\
3.01,7.72\end{array}$ & $\begin{array}{c}1.22 \pm 0.98 \\
0.06,7.81\end{array}$ & $\begin{array}{l}1.14 \pm 1.12 \\
0.07,10.37\end{array}$ \\
\hline $\begin{array}{c}\boldsymbol{H}_{\text {top }} \pm \text { std } \\
\text { min, max }\end{array}$ & $\begin{array}{c}1.62 \pm 0.63 \\
0.29,3.0\end{array}$ & $\begin{array}{c}4.88 \pm 0.68 \\
3.17,6.0\end{array}$ & $\begin{array}{c}4.29 \pm 0.89 \\
1.39,5.99\end{array}$ & $\begin{array}{c}9.75 \pm 2.13 \\
6.20,18.79\end{array}$ & $\begin{array}{l}7.93 \pm 1.27 \\
5.47,17.98\end{array}$ & $\begin{array}{l}7.81 \pm 1.35 \\
3.62,17.38\end{array}$ & $\begin{array}{l}8.93 \pm 1.66 \\
1.79,17.56\end{array}$ \\
\hline $\begin{array}{c}\boldsymbol{L W P} \pm \mathbf{s t d} \\
\operatorname{Max} L W P\end{array}$ & $\begin{array}{c}122.4 \pm 134.2 \\
1470.8\end{array}$ & $\begin{array}{c}86.7 \pm 124.5 \\
501.1\end{array}$ & $\begin{array}{c}168.7 \pm 236.7 \\
1937.1\end{array}$ & $\begin{array}{l}1 \\
1\end{array}$ & $\begin{array}{c}40.9 \pm 40.8 \\
345.7\end{array}$ & $\begin{array}{c}169.2 \pm 238.4 \\
1819.3\end{array}$ & $\begin{array}{c}129.8 \pm 202 . \\
1785.2\end{array}$ \\
\hline $\begin{array}{c}\boldsymbol{L W P} \pm \text { std } \\
\text { (single layer) } \\
\max \end{array}$ & $\begin{array}{c}126.6 \pm 138.1 \\
1470.8\end{array}$ & $\begin{array}{c}88.7 \pm 128.9 \\
501.1\end{array}$ & $\begin{array}{c}193.1 \pm 271.9 \\
1937.1\end{array}$ & I & $\begin{array}{c}48.7 \pm 51.7 \\
345.7\end{array}$ & $\begin{array}{c}270.8 \pm 349.5 \\
1819.3\end{array}$ & I \\
\hline $\begin{array}{c}\text { LWP } \pm \text { std } \\
\text { (multi-layer) } \\
\max \end{array}$ & $\begin{array}{c}96.2 \pm 103.4 \\
842.3\end{array}$ & $\begin{array}{c}77.2 \pm 109.2 \\
305.6\end{array}$ & $\begin{array}{c}139.0 \pm 180.7 \\
1830.2\end{array}$ & I & $\begin{array}{c}32.3 \pm 21.3 \\
86.8\end{array}$ & $\begin{array}{c}148.4 \pm 202.4 \\
1690.7\end{array}$ & $\begin{array}{c}129.8 \pm 202 . \\
1785.2\end{array}$ \\
\hline $\begin{array}{c}\text { Multi-layer } \\
\text { percentage \% }\end{array}$ & 18.1 & 39.6 & 50.0 & 44.9 & 73.1 & 77.7 & 100 \\
\hline
\end{tabular}

* The definition of the cloud types as follow: LOW $\left(H_{\text {base }}\right.$ and $\left.H_{\text {top }} \leq 3 \mathrm{~km}\right)$; MID $\left(H_{\text {base }}>\right.$ $3 \mathrm{~km}$ and $\left.H_{\text {top }} \leq 6 \mathrm{~km}\right)$; HGH $\left(H_{\text {base }}>6 \mathrm{~km}\right)$; MOL $\left(H_{\text {base }}<3 \mathrm{~km}\right.$ and $\left.H_{\text {top }} \leq 6 \mathrm{~km}\right)$; HOM ( $3 \mathrm{~km}<H_{\text {base }}<6 \mathrm{~km}$ and $H_{\text {top }}>6 \mathrm{~km}$ ); HML ( $H_{\text {base }}<3 \mathrm{~km}, H_{\text {top }} \geq 6 \mathrm{~km}$ with a MID layer); HOL (LOW and HGH appear at the same time). 
Table 2a. Comparison of cloud phase identifications between our classification method and Shupe et al. (2005) method in each 5-min measurements, the unit is number of 5-min samples.

\begin{tabular}{|l|l|l|l|}
\hline Shupe / this study & Liquid (this study) & $\begin{array}{l}\text { Mixed-phase (this } \\
\text { study }\end{array}$ & Ice (this study) \\
\hline Liquid & 468 & 490 & 0 \\
\hline Mixed-phase & 98 & $\mathbf{3 8 4 0}$ & 0 \\
\hline Ice & $\mathbf{8 1}$ & 0 & 1195 \\
\hline
\end{tabular}

*Numbers denote the cloud sample classifications between two methods. For example, the number 98 denote a total of 98 samples are classified as Mixed-phase using Shupe's method, while are classified as Liquid using this study's method.

Table 2b. The cloud phase partitioning from CDP and 2DS during SOCRATES. Cloud Droplet Probe (CDP) measures particle size from 2 to $50 \mathrm{um}$ in diameter; Two-Dimensional Stereo Probe (2DS) measures particle size from 50 to $5000 \mathrm{um}$ in diameter.

\begin{tabular}{|l|l|l|l|}
\hline Phase partitioning & 1 second & 10 seconds & 30 seconds \\
\hline Samples \# & 27280 & 2255 & 836 \\
\hline Liquid, \% & $\mathbf{5 8 . 8}$ & 26.2 & 18.8 \\
\hline Mixed-phase, \% & $\mathbf{3 8 . 9}$ & 69.1 & 77.0 \\
\hline Ice, \% & 2.3 & 4.7 & 4.2 \\
\hline
\end{tabular}


Table 3. Liquid, mixed, ice and OTHER phases of cloud properties within the singlelayered low-level clouds

\begin{tabular}{|c|c|c|c|c|c|c|}
\hline Phase & Samples & $\boldsymbol{H}_{\text {base }}, \mathbf{k m}$ & $\boldsymbol{H}_{\text {top }}, \mathbf{k m}$ & $\Delta \boldsymbol{H}, \mathbf{~ k m}$ & $\boldsymbol{L W P}, \mathbf{g ~ m}^{-\mathbf{2}}$ & $\boldsymbol{P W} \boldsymbol{V}, \mathbf{~ m m}$ \\
\hline Liquid & 697 & $0.424 \pm 0.204$ & $1.327 \pm 0.242$ & 0.903 & $113.6 \pm 90.1$ & $15.7 \pm 3.5$ \\
\hline Mixed & 3777 & $0.834 \pm 0.465$ & $1.434 \pm 0.617$ & 0.587 & $119.7 \pm 136.6$ & $8.9 \pm 5.0$ \\
\hline Ice & 1205 & $1.218 \pm 0.635$ & $1.737 \pm 0.651$ & 0.519 & 0 & $8.4 \pm 4.5$ \\
\hline OTHER & 1255 & $0.700 \pm 0.454$ & $1.774 \pm 0.571$ & 1.074 & $141.9 \pm 137.5$ & $11.4 \pm 5.9$ \\
\hline
\end{tabular}




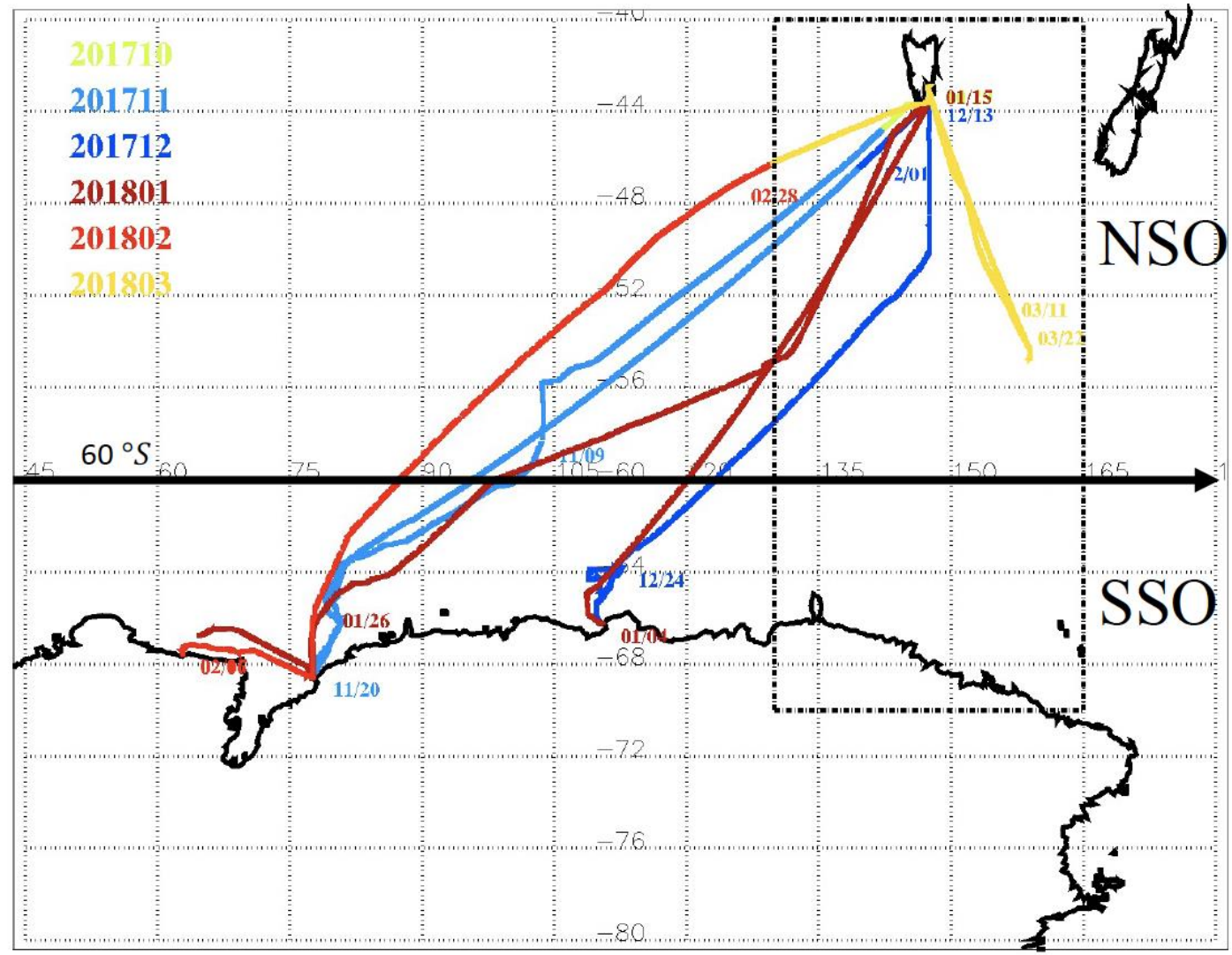

Figure 1. Shiptrack measurements between Hobart, Australia and Antarctica. Different colors represent different month's shiptracks from Oct. 29, 2017 to Mar. 23, 2018 during MARCUS. Along the shiptracks, the study domain is separated into northern (NSO) and southern (SSO) parts of the Southern Ocean with a demarcation line of $60^{\circ} \mathrm{S}$ in order to study the clouds over the midlatitudes (North of $60{ }^{\circ} \mathrm{S}$ ) and Polar region (South of $60^{\circ} \mathrm{S}$ ). The black dotted rectangle represents the SOCRATES study domain. Some of the dates have labeled along the shiptracks, which can indicate the direction of the ship traveled. 


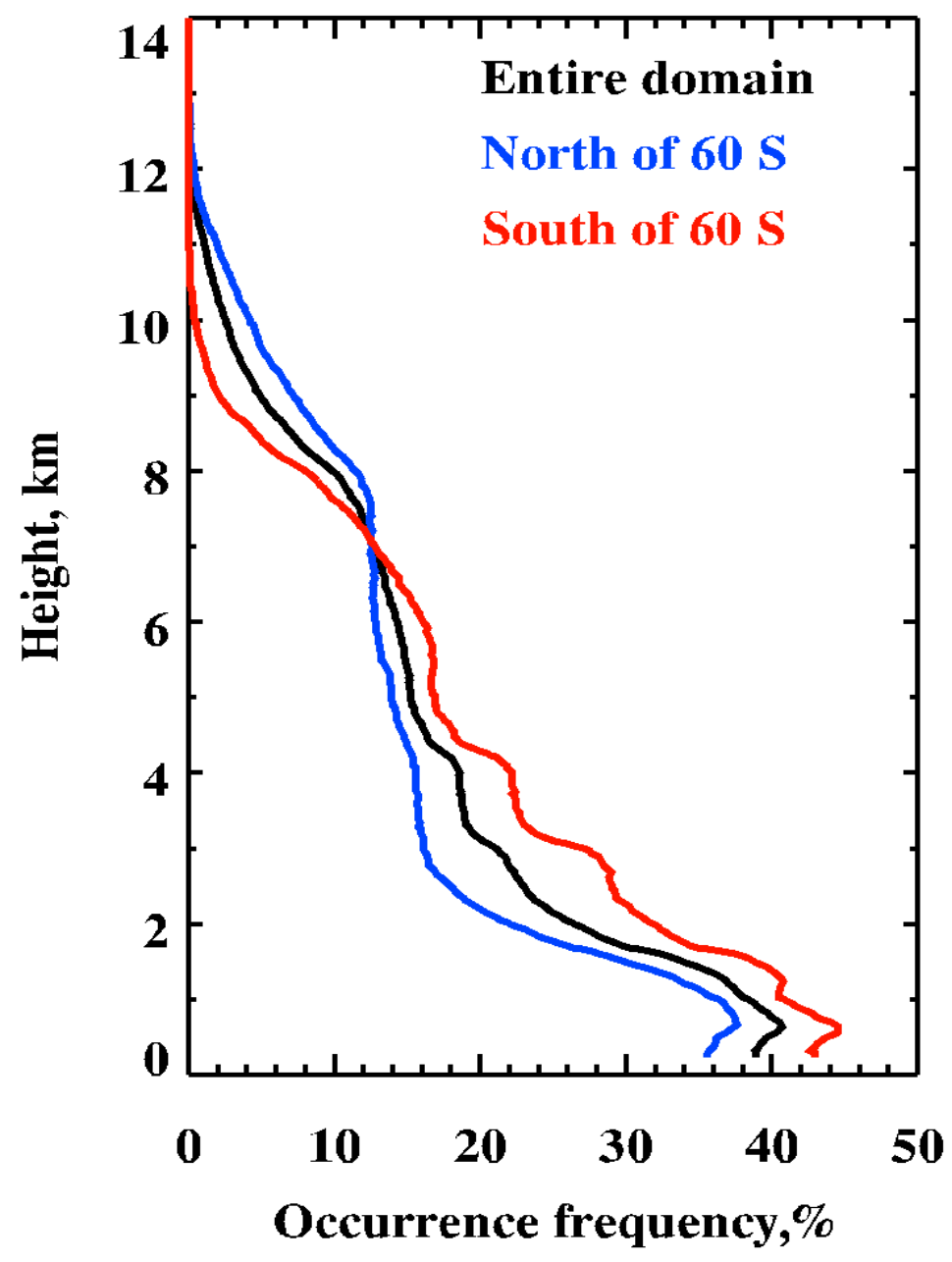

Figure 2. Mean vertical distributions of total clouds derived from ARM radar-lidar observations with a 5-min temporal resolution and a 30-m vertical resolution during MARCUS. 

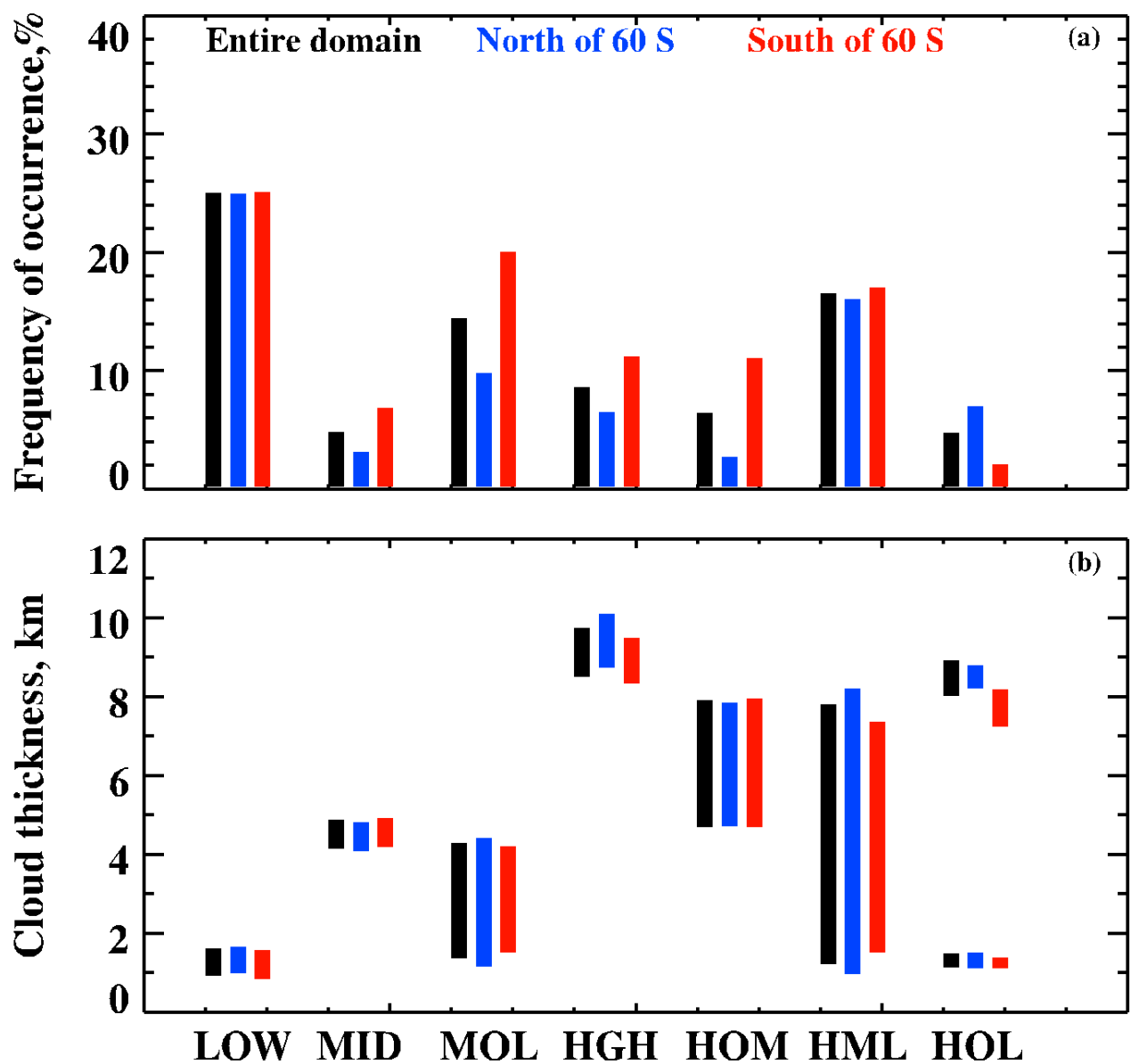

Figure 3. (a) Occurrence frequencies of categorized clouds by their vertical structures. LOW, single - layered low clouds $\left(H_{\text {base }}\right.$ and $\left.H_{\text {top }} \leq 3 \mathrm{~km}\right)$; MID, single-layered middle clouds $\left(H_{\text {base }}>\right.$ $3 \mathrm{~km}$ and $\left.H_{\text {top }} \leq 6 \mathrm{~km}\right)$; MOL, MID over LOW ( $H_{\text {base }}<3 \mathrm{~km}$ and $\left.H_{\text {top }} \leq 6 \mathrm{~km}\right)$; HGH, singlelayered high clouds $\left(H_{\text {base }}>6 \mathrm{~km}\right)$; HOM, HGH over MID $\left(3 \mathrm{~km}<H_{\text {base }}<6 \mathrm{~km}\right.$ and $H_{\text {top }}>$ $6 \mathrm{~km})$; HML, HGH over MID and LOW ( $H_{\text {base }}<3 \mathrm{~km}, H_{\text {top }} \geq 6 \mathrm{~km}$ with a MID layer); and HOL, HGH over LOW (LOW and HGH appear at the same time). (b) Cloud thickness for each type of clouds (bar), the top and bottom of the bar represent the maximum cloud-top and minimum cloudbase heights, respectively. Black, blue, and red bars represent the entire domain (Lat:41-69 ${ }^{\circ} \mathrm{S}$; Long: $60-160^{\circ} \mathrm{E}$ ), north of $60^{\circ} \mathrm{S}$ (NSO), and south of $60^{\circ} \mathrm{S}$ (SSO), respectively, during the MARCUS field campaign (10/2017-3/2018). 

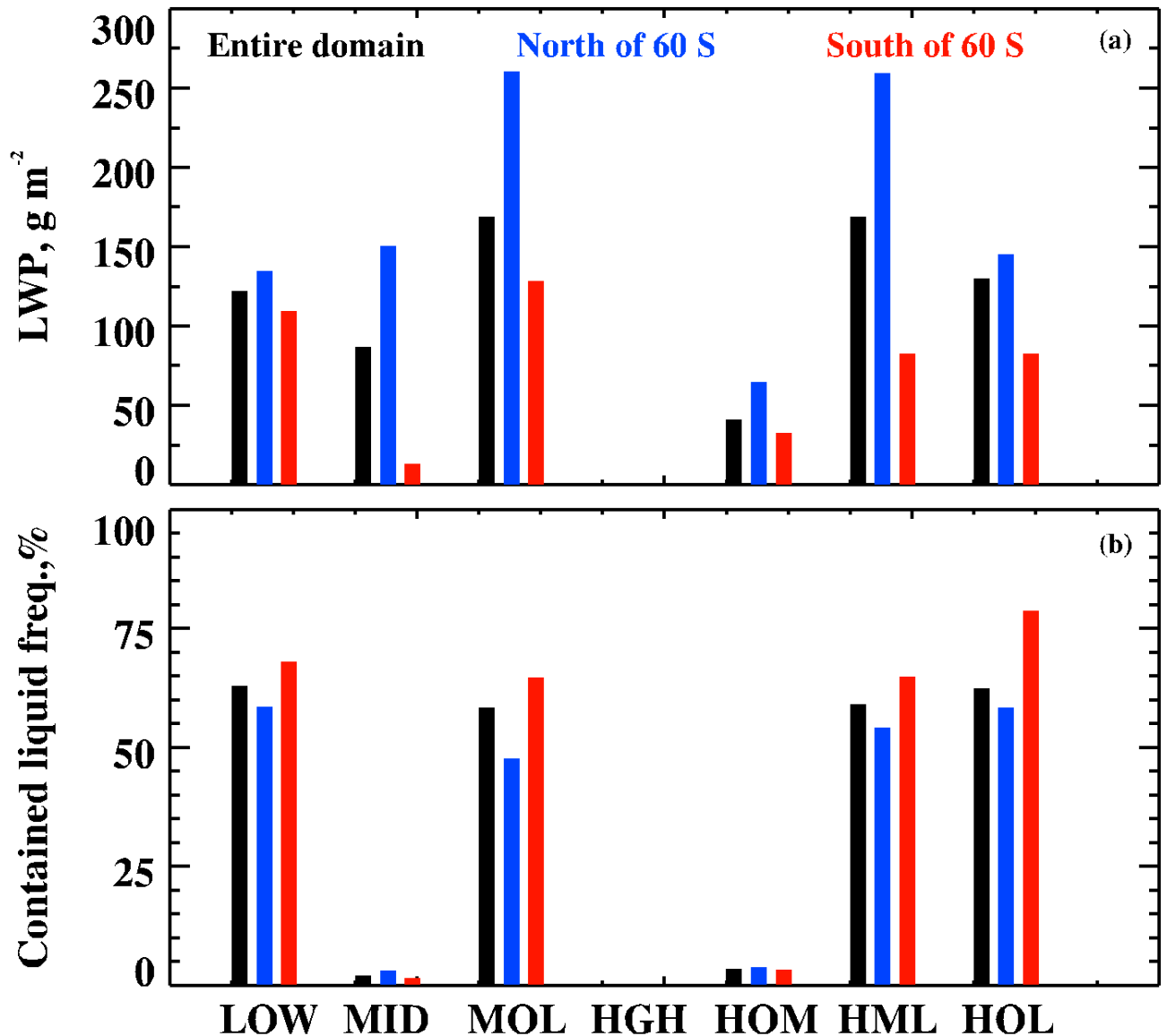

Figure 4. (a) Cloud liquid water paths ( $L W P s$ ) retrieved from microwave radiometer (MWR) measured brightness temperature using a physical retrieval method for each type of cloud. (b) The occurrence frequencies of LWPs> $10 \mathrm{gm}^{-2}$ for each type of clouds 


\section{Phase classification algorithm for single lavered low level clouds}

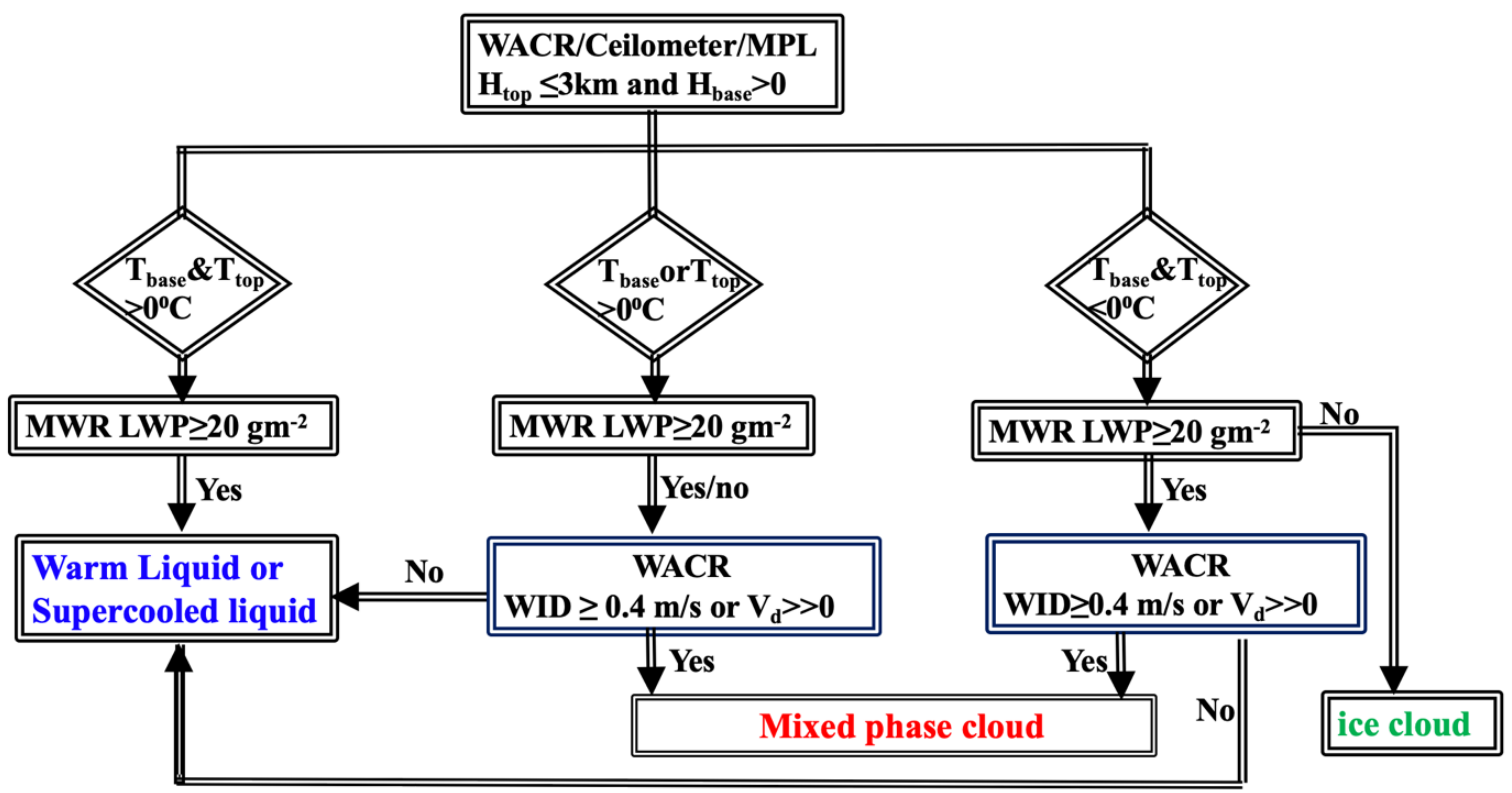

Figure 5. A flow chart for phase classification of single-layered low-level clouds. W-Band (95 GHz) ARM Cloud Radar (WACR) provides radar spectrum width (WID) and Doppler velocity $\left(V_{\mathrm{d}}\right)$. 

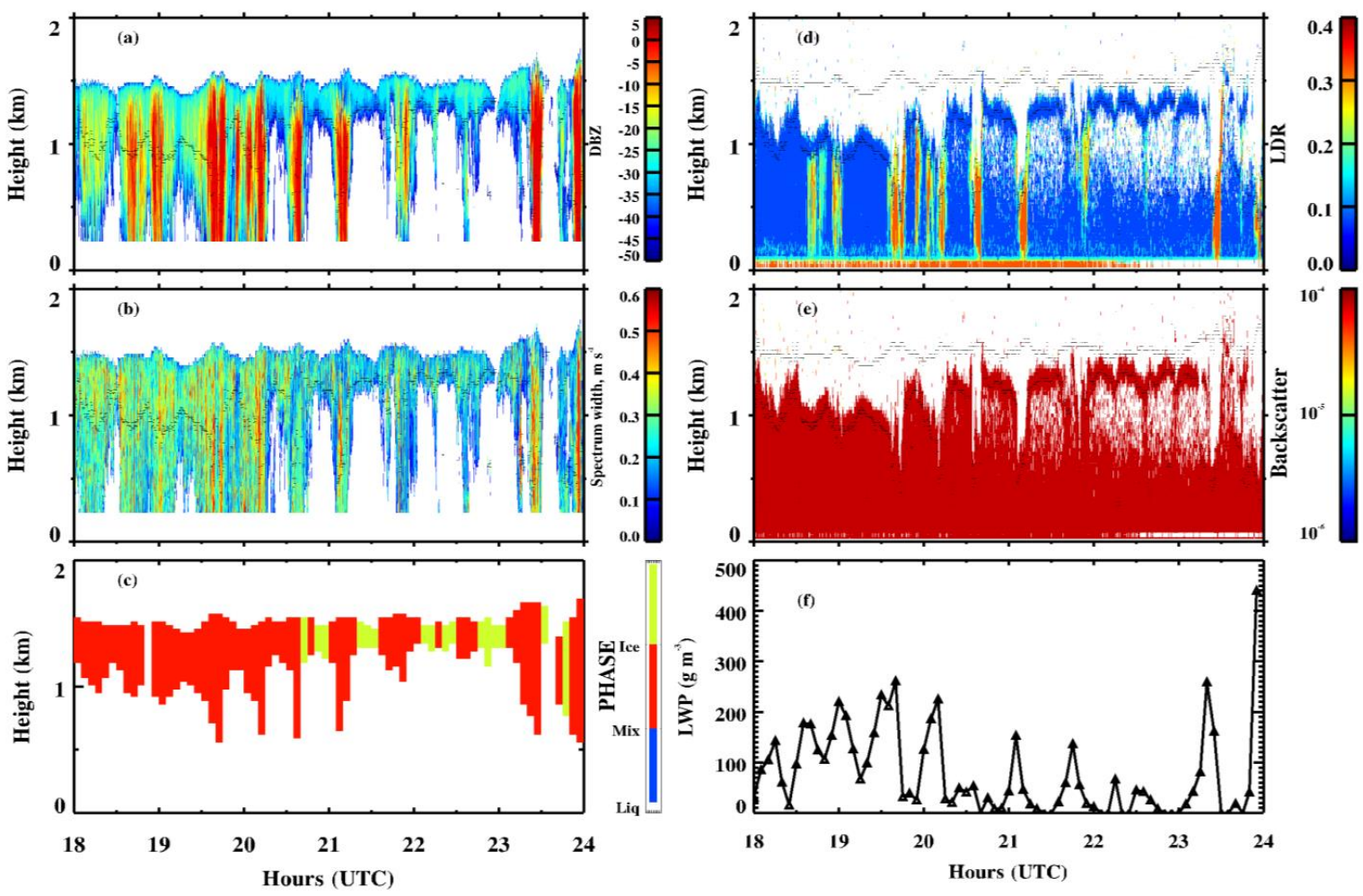

Figure 6. A case study that shows our phase classification (left column) and Micropulse Lidar linear depolarization ratios $(L D R)$ and backscatter. W-Band $(95 \mathrm{GHz})$ ARM Cloud Radar (WACR) reflectivity shows in (a) and spectrum width shows in (b); The phase classification shows in (c); MPL LDR shows in (d) and backscatter shows in (e); and LWP shows in (f). 

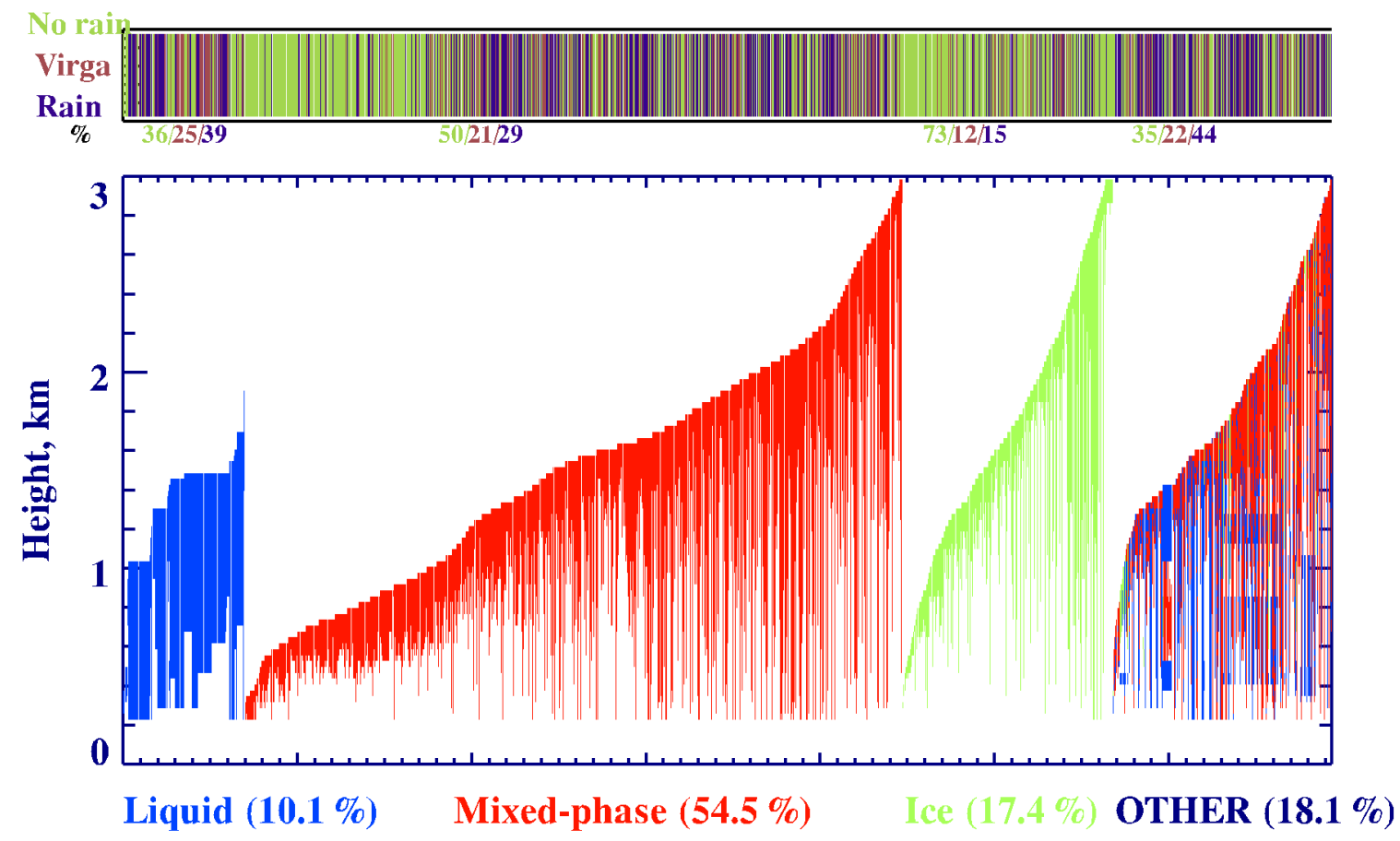

Figure 7. (Upper Panel) The drizzling status for each categorized cloud type, e.g., no rain (yellowgreen), virga (brown) and rain (navy blue), the percentages shown below the $\mathrm{x}$-axis represent the portion of drizzling in each type of clouds; And (Bottom Panel) the percentages and vertical distributions of classified liquid, mixed-phase, ice, and 'OTHER' clouds for each column in the single-layered low-level clouds, represented by different colors, over the entire domain during MARCUS. Each line represents one 5-min sample. 

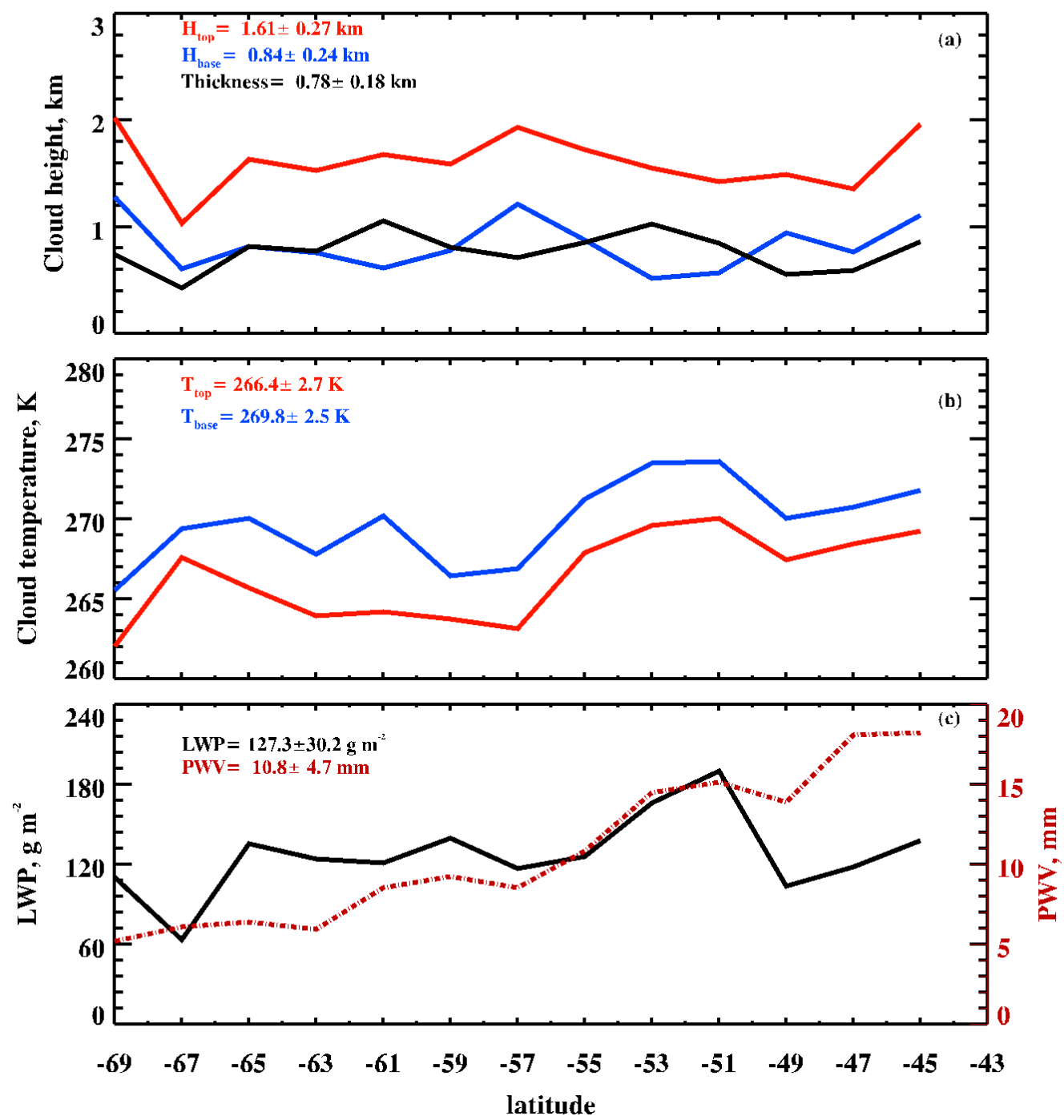

Figure 8. Meridional variations of single-layered low-level cloud properties: (a) cloud-base ( $\left.H_{\text {base }}\right)$ and -top $\left(H_{\text {top }}\right)$ heights, and cloud thickness $(\Delta H)$, (b) cloud-base ( $\left.T_{\text {base }}\right)$ and -top $\left(T_{\text {top }}\right)$ temperatures, and (c) cloud liquid water path ( $L W P$ ) and precipitable water vapor (PWV) over the entire domain during MARCUS. 


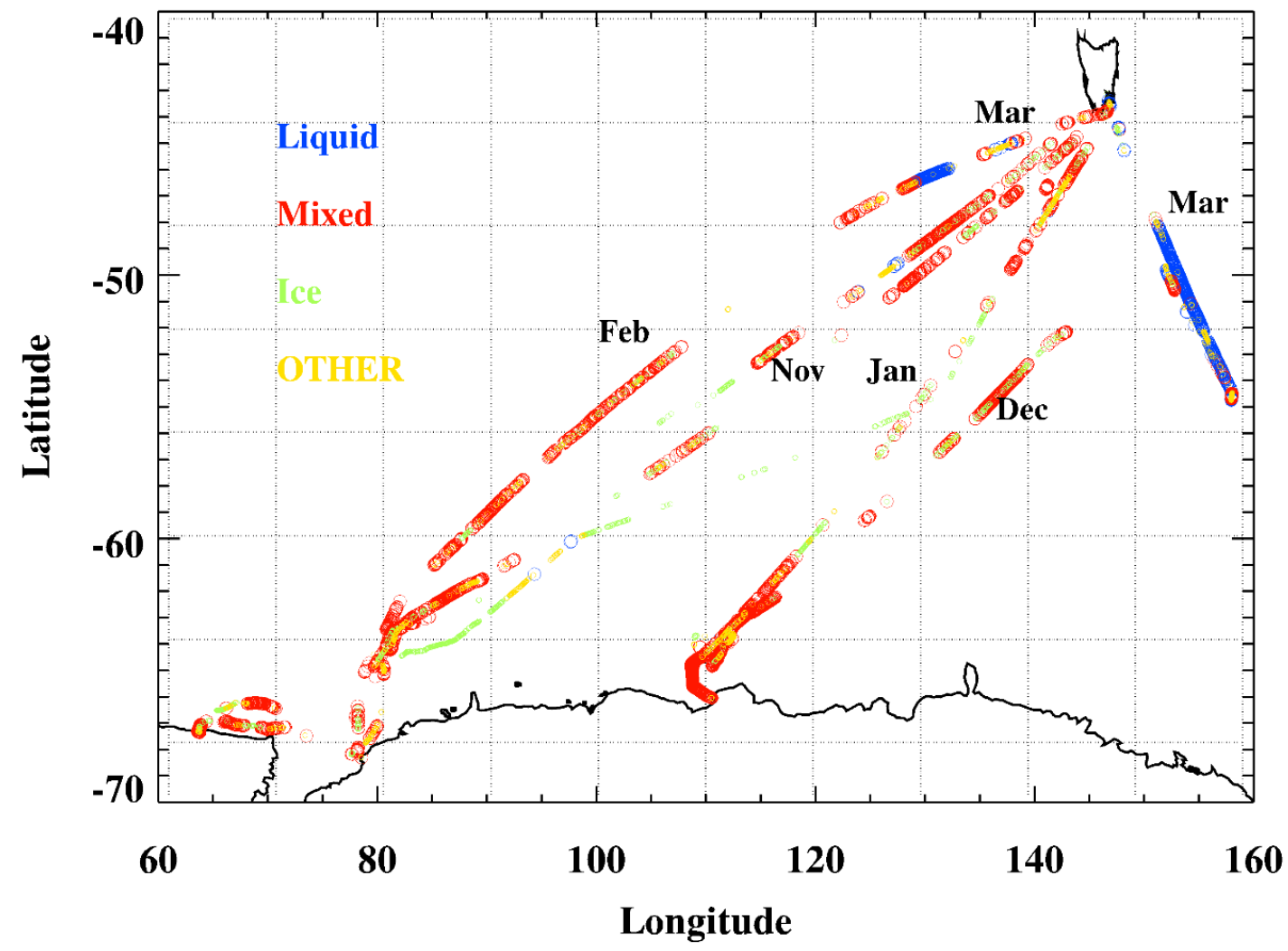

Figure 9. The latitudinal and longitudinal distributions of classified mixed-phase, liquid, and ice clouds in the single-layered low-level clouds. The liquid (blue), mixed (red), ice (light green), and OTHER (yellow) are shown along each shiptrack from October 2017 to March 2018 during MARCUS. 

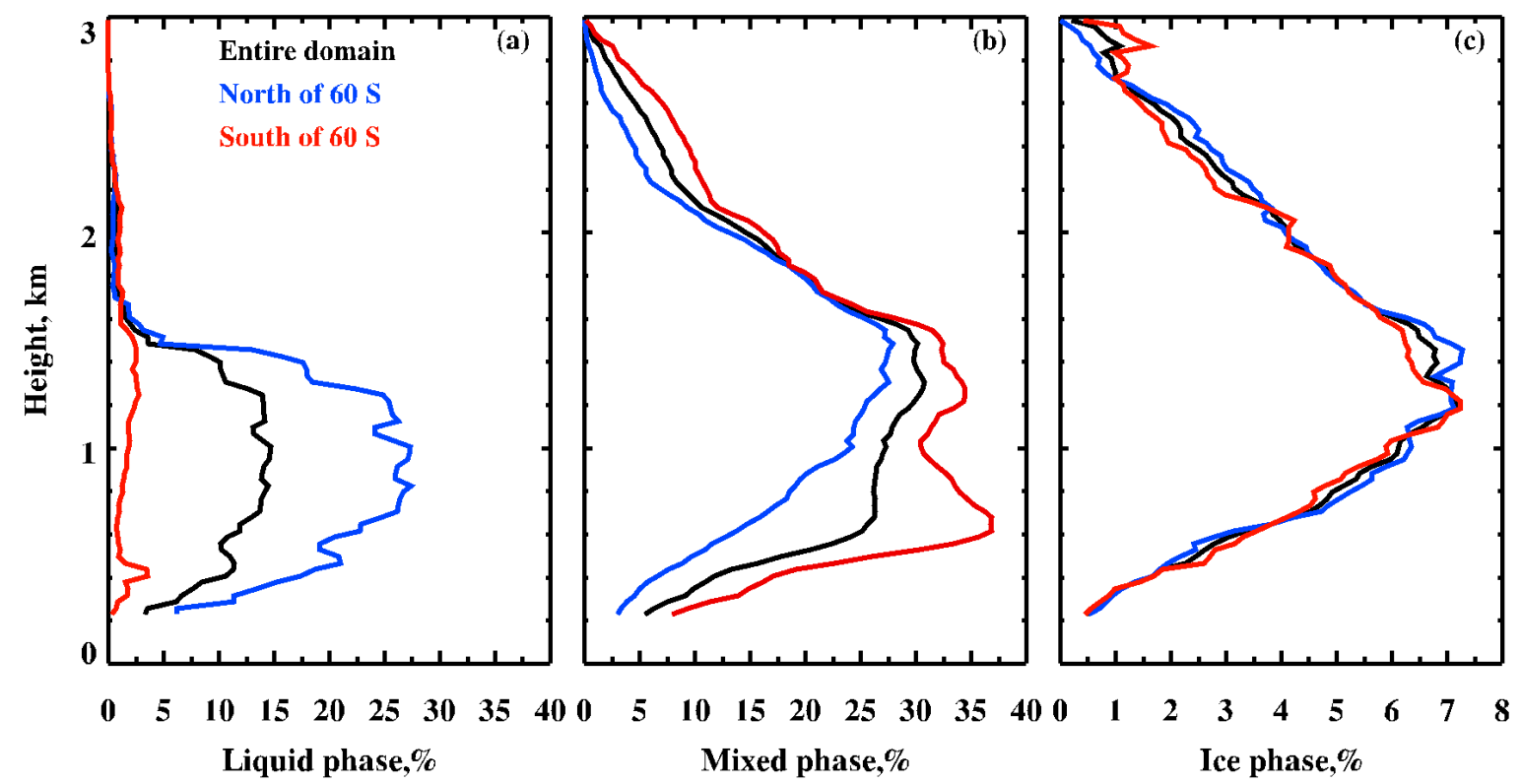

Figure 10. Occurrence frequencies of classified mixed-phase, liquid, and ice clouds over the entire domain (black), North of $60^{\circ} \mathrm{S}$ (blue) and South of $60{ }^{\circ} \mathrm{S}$ during MARCUS. 

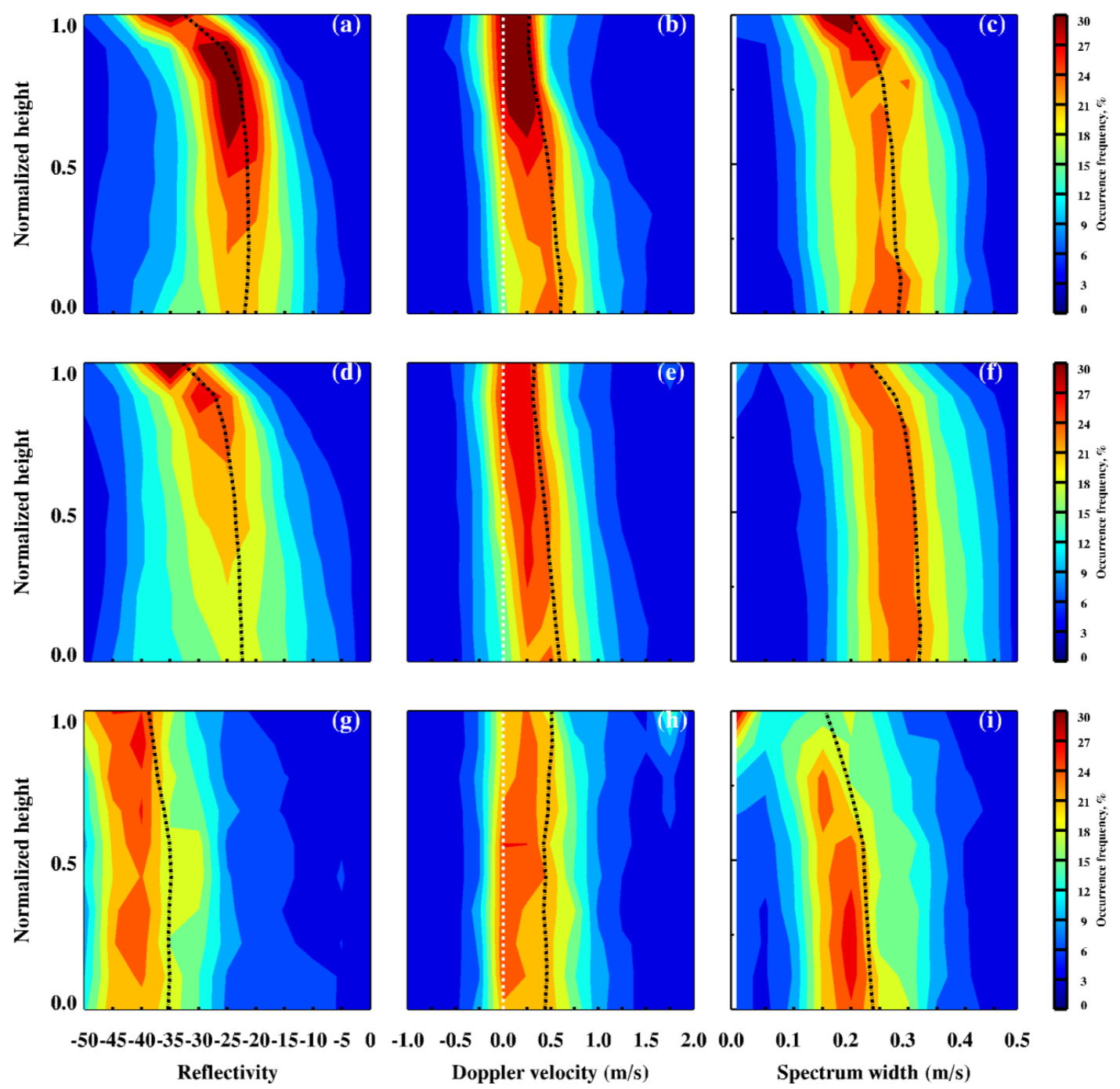

Figure 11. Normalized vertical distributions of a) radar reflectivity, b) Doppler velocity and c) spectrum width for the classified liquid (upper panel), mixed-phase ( $\mathrm{d}$ to $\mathrm{f}$, middle panel) and ice ( $\mathrm{g}$ to $\mathrm{i}$, bottom panel) clouds over the North of $60^{\circ} \mathrm{S}$ during MARCUS IOP. Normalized height is defined as $=\frac{H-H_{\text {base }}}{H_{\text {top }}-H_{\text {base }}}$ where cloud base is denoted as 0 and cloud top is 1 . The black lines represent the median values and the white lines in Doppler velocity represent the reference of 0.0 $\mathrm{m} \mathrm{s}^{-1}$. 
https://doi.org/10.5194/amt-2021-388

Preprint. Discussion started: 17 January 2022

(c) Author(s) 2022. CC BY 4.0 License.
Atmospheric Measurement Techniques

Discussions
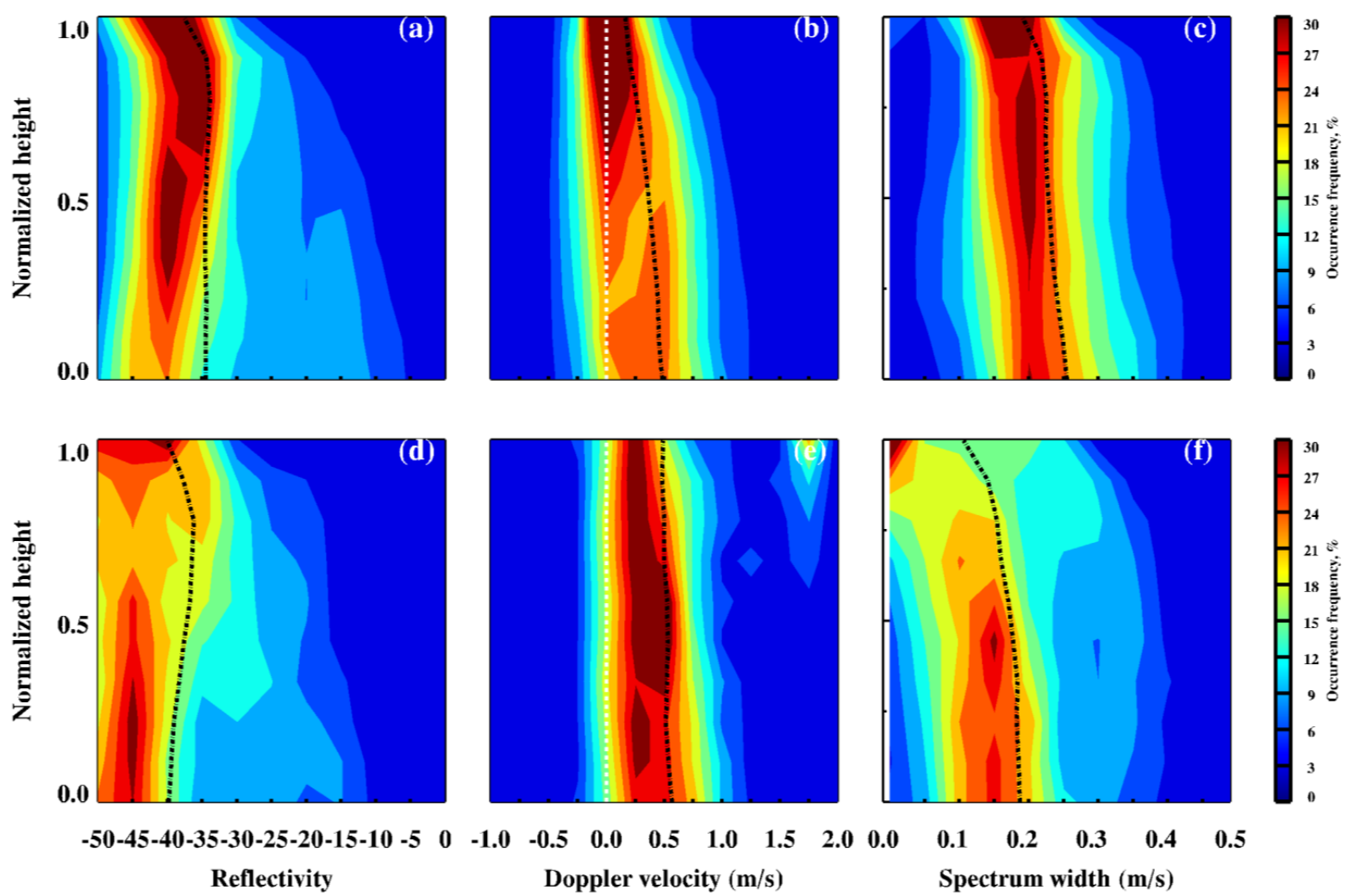

Figure 12. Same as Fig. 11 but only for mixed-phase (a to c, upper panel) and ice (d to f, bottom panel) over the south of $60{ }^{\circ} \mathrm{S}$ during MARCUS. 